\title{
Metabolic Allometry during Development and Metamorphosis of the Silkworm Bombyx mori: Analyses, Patterns, and Mechanisms
}

\author{
Bonnie L. Blossman-Myer \\ Warren W. Burggren \\ Department of Biology, University of North Texas, 1510 \\ North Chestnut Street, Denton, Texas 76203 \\ Accepted 9/13/2009; Electronically Published 1/27/2010
}

\begin{abstract}
Intraspecific allometric (scaling) relationships for metabolism, which have received little examination compared to interspecific relationships, reflect a complex interplay of organogenesis, growth, and shifting physiologies. In this study of the silkworm Bombyx mori, we hypothesized that allometric relationships for metabolism both across all developmental stages and within each stage would not reflect conventional scaling coefficients (e.g., $b \neq 0.75$ ). Histology, gross morphology, body surface and cross-sectional area, total lipid content, and cytochrome $c$ oxidase activity levels (as evidence of the total metabolic potential of mitochondria) were determined across development. Also measured were oxygen consumption, carbon dioxide production, and the respiratory exchange ratio. The overall slope, $b$, in the allometric equation relating to body mass across all developmental stages was 0.82 , not greatly different from the value of 0.75 typical of interspecific data. However, within larval instars II-V and in prepupae, $b$ varied between 0.99 and 1.49, far higher than hypothesized. Thus, in B. mori, an analytical approach that lumps all developmental stages hides interinstar variability. Morphological and biochemical data suggest that observed scaling patterns in $B$. mori are likely correlated with changes in overall mitochondrial density rather than with specific changes in body proportion of tissues with higher intrinsic metabolic intensity.
\end{abstract}

\section{Introduction}

Allometry has been a mainstay of physiological investigation for more than a century. The great majority of studies have focused on the metabolic allometry of adults of different species, yielding the familiar "mouse-to-elephant" relationship. While the general phenomenon of metabolic scaling has been

\footnotetext{
*Corresponding author; e-mail: bmyer@unt.edu.
}

Physiological and Biochemical Zoology 83(2):215-231. 2010. (C) 2010 by The University of Chicago. All rights reserved. 1522-2152/2010/8302-8188\$15.00 DOI: $10.1086 / 648393$ demonstrated repeatedly, its precise nature and underlying causes are still not well understood. Kleiber (1932) reported that a proportionality exponent of 0.75 applied to metabolic scaling relationships in mammals. Later, this mass exponent was extended to a wide variety of poikilothermic organisms (see Wieser 1984). Heusner (1982), however, challenged the 0.75 scaling exponent advocated by Kleiber (1932), declaring it a statistical artifact. Instead, Heusner (1982) argued that the overall 0.75 scaling coefficient was created from individual parallel regression lines of 0.67 that followed the so-called Surface Law but that an average scaling coefficient of 0.75 resulted when these individual regression lines were analyzed together via a regression model. Feldman and McMahon (1983) disagreed with Heusner's (1982) interpretation and defended Kleiber's. Wieser (1984) then suggested that the controversy may be due to the lack of distinction between intraspecific and interspecific allometry or between use of whole-animal and mass-specific rates in metabolic allometry. White and Seymour (2003) reported that mammalian metabolic rate scales according to the Surface Law and that the quarter-power scaling law is flawed because animals are not measured in similar physiological states relating to activity level, specific dynamic action, circadian rhythms, environmental temperature, developmental and reproductive stages, and thermal conditions. Variation in metaanalyses of allometric data may also arise from interspecific variation in the amount of metabolically active tissue contributing to what is determined to be "body mass" (Schmidt-Nielsen 1984; Wang et al. 1992; Glazier 2005; Hulbert and Else 2005; Davies and Moyes 2007). Indeed, complex metazoans typically comprise multiple body compartments whose tissues exhibit varying rates of oxygen consumption. As body mass increases, organs having a very high oxygen uptake (e.g., neural tissue) may not increase in the same proportion as organs that contribute least to oxygen uptake (e.g., bone; Hulbert and Else 2005; Hunt von Herbing 2006). Wang et al. (1992) went so far as to subdivide an animal's body into five major classes: atomic, molecular, cellular, tissue system, and the whole body, each characterized by potentially differing allometric relationships. More simply, animals can be compartmentalized by lean body mass (high metabolic activity) and fat body mass (low metabolic activity; Hunt von Herbing 2006). Not surprisingly, metabolic rate correlates more closely with lean body mass than with whole-organism mass (Hunt von Herbing 2006). Thus, for a multitude of reasons - analytical, physiological, and biochemical-a long-standing controversy has persisted over the 0.75 and 0.67 scaling exponents of metabolic rate as a function of body size in adult animals (for an entry into the extensive literature, see West et al. 2002; Agutter and Wheatley 2004; 
Kozłowski and Konarzewski 2004; Economo et al. 2005; Glazier 2005; West and Brown 2005; Seibel 2007; Moses et al. 2008).

If uncertainty exists as to the precise nature of metabolic scaling and its mechanistic underpinnings in comparing adults of different sizes, then the situation is even more complex in intraspecific analyses involving developing animals. While metabolic rate is dependent on many factors, both intrinsic and extrinsic (e.g., temperature, activity level, reproduction, and locomotion, as well as the cost of transport and energy utilization), growth is a major factor in any consideration of intraspecific allometry in a wide variety of species, including molluscs, fishes, reptiles, and mammals (see Glazier 2005 for a review; also Moran and Wells 2007; Moran et al. 2007; Seibel 2007; Czarnołęski et al. 2008; Toledo et al. 2008). A basic principle of metabolic allometry is that, ideally, animals are in an identical physiological state when measured, yet a basic principle of development is that physiological state is constantly changing (Burggren 2005), especially in situations of rapid and/ or extreme growth. Thus, faced with this "impasse of principles" (Burggren 2005), we may simply not be able to evoke the same general allometric principles and models established for comparisons of different-sized adults of different species when considering developing animals (Smith 1984; Burggren 2005; Hunt von Herbing 2006). Significantly, few approaches have attempted to control simultaneously for both growth (body mass increase) and development (cell, tissue, and organ differentiation). Developing animals undergoing some form of metamorphosis may show especially confounding changes in body composition associated with dramatic tissue growth, tissue differentiation, and energy storage, all of which may have complex effects on metabolic scaling. This may explain why, then, intraspecific allometric studies on metabolism have yielded highly variable results (Withers 1992; Glazier 2005), and it sows seeds of doubt that there exists a universal conceptual framework explaining all aspects of allometry in all animals (including immature ones).

Insects are a good model for investigating intraspecific allometry because they have important developmental characteristics that make them well suited for the study of interactions of growth and development. Most significant are their typically discrete stages of development, characterized by highly distinctive morphological markers and behaviors (e.g., ecdysis). Large ranges of body mass aid allometric studies, and many insects exhibit as many as four orders of magnitude of body mass growth from egg to adult. Of course, fundamental morphological reorganization associated with ongoing differentiation occurs during metamorphosis in insects, adding further complexity (and therefore further interest) to intraspecific allometric studies. Not surprisingly, then, there have been numerous studies of various aspects of intraspecific allometry in insects (e.g., Schroeder and Dunlap 1970; Beckage et al. 1997; Greenlee and Harrison 2004a, 2004b, 2005; Hetz 2007). These papers have primarily concentrated on patterns of respiration, isolated measurements of metabolic rate, and morphological aspects such as the allometry of the tracheal system, as opposed to a detailed instar-by-instar assessment of metabolic rate.
In this study, we have investigated intraspecific morphological and metabolic allometry of the silkworm Bombyx mori, measuring oxygen consumption and carbon dioxide production during successive life-cycle stages from larval instars I-V through the prepupal and pupal stages. Our intent was to determine whether metabolic rates during development showed patterns predicted by standard interspecific allometric data and also whether metabolic patterns within instars would be different than those between instars. We first hypothesized that metabolic allometric patterns in the multiple stages of developing Bombyx would not be accurately predicted by use of standard interspecific scaling exponents (Kleiber's law, body surface law) because of gas exchange limitations; for example, it was recently demonstrated that tracheal surface area remains static even as body mass increases within instars (see Greenlee and Harrison 2004a; Harrison et al. 2005). Such a limitation could lead to a relatively large decline in metabolic rate within an instar, reflected in a lower-than-expected value of the slope $b$ in the allometric equation. We tested this hypothesis by measuring oxygen uptake both within and between instars. We then predicted that stage-dependent relationships between metabolic rate and body mass can be predicted from changing lipid stores, fundamental tissue growth, and remodeling and apoptosis associated with larval development, pupation, and metamorphosis. Specifically, we hypothesized that changes in metabolic rate during ontogeny would mirror changes in the proportion of the most metabolically active tissues (i.e., those with the least fat and water). We tested this hypothesis by measuring changes in structural and biochemical body composition in developing silkworms, using histological and gross morphology and determination of total lipid content and cytochrome c oxidase activity levels (the latter as evidence of the total metabolic potential of mitochondria).

\section{Material and Methods}

\section{Life History of Bombyx mori}

The life cycle of Bombyx mori is completed in $~ 55 \mathrm{~d}$ (Ganga 2003). It comprises an embryonic egg stage, larval instars I-V (designated L-I-L-V), and prepupal (PP), pupal, and adult stages. After an embryonic incubation period of $\sim 10 \mathrm{~d}$, L-I (typically $3 \mathrm{~mm}$ long and $0.0004 \mathrm{~g}$ in body mass) hatch within $24 \mathrm{~h}$ and begin feeding. The five successive larval instars are behaviorally and morphologically separated by ecdysis (molting). Prepupae, having grown to $\sim 2$ g, prepare for metamorphosis by constant feeding to provide energy storage. At the end of the PP stage, the larva searches for an appropriate site to spin a cocoon of silk to surround its body. Once the cocoon is formed, the larva secretes a hard outer cuticle, and metamorphosis commences. Metamorphosis is a complex process that includes hyperplastic and hypertrophic growth as well as apoptosis and histolysis of specific larval tissues. After about $10 \mathrm{~d}$, the adult emerges out of the cocoon, in a process termed "eclosion." Adults immediately copulate, and the female lays eggs. Adults have no functional mouth parts and do not feed, dying within $5 \mathrm{~d}$ of hatching and mating. 
Animal Husbandry

Fertilized silkworm eggs obtained from Carolina Biological Supply (Burlington, NC) were placed in petri dishes and incubated in transparent incubators at a temperature of $25^{\circ} \pm$ $0.5^{\circ} \mathrm{C}$ and a relative humidity of $60 \% \pm 5 \%$. Incubators were illuminated with a $12 \mathrm{~L}: 12 \mathrm{D}$ photoperiod. Petri dishes were examined for hatched larvae each morning, since hatching occurs in the morning because of circadian rhythms of metabolism and eclosion hormone secretion (Fugo et al. 1984). Newly hatched L-I were transferred into date-labeled petri dishes. All larval instars were fed an artificial silkworm diet obtained from Carolina Biological Supply. Food remaining in the petri dishes was removed each evening.

\section{Histological Preparation}

Whole animals were fixed with $10 \%$ neutral buffered formalin for a minimum of $2 \mathrm{~h}$ before dehydration. The specimens were fixed in formalin, dehydrated, and infiltrated with paraffin in a microwave rapid histoprocessor (Milestone RH1; Sorisole, Italy) and then embedded in paraffin blocks (Shandon Histocentre 3 tissue embedder; Pittsburgh). A microtome (Leitz 1512; Bannockburn, IL) was used to cut whole-body cross sections between body segments 1 and 2 (middle/cranial region) and between segments 6 and 7 (middle/caudal region). Ribbons were mounted on labeled slides in a $45^{\circ} \mathrm{C}$ Fisher tissue float bath and allowed to air dry for $24 \mathrm{~h}$. Tissue was rehydrated and stained with $\mathrm{H} \& \mathrm{E}$ (hematoxylin and eosin) stain. Slides were mounted with Cytoseal XYL and allowed to dry for 24 h.

\section{Surface Area Calculation}

Total-body cross-sectional surface area (CSA) and midgut-wall CSA were calculated from microscope images of whole-body cross sections mounted on microscope slides. Imaging software (ImagePro, Bethesda, MD) allowed direct calculation of the area enclosed by an outline traced on either the whole body or the gut on the images. Midgut-wall CSA included the midgut tissue only; the lumen area was excluded. In general appearance, larval Bombyx appear cylindrical. To test this supposition, CSA was measured at the junctions of segments 1 and 2 and then again at the junction of segments 6 and 7. Mean CSA of body segments $1-2$ was not significantly different $(P>0.05)$ from that of segments 6-7 within any larval stage, suggesting that each instar grew primarily by elongation rather than by differential changes from anterior to posterior. Consequently, CSAs from the segments were averaged to produce a single CSA representing the individual. Body length of specimens of each larval stage was measured with a micrometer. Total-body surface area of the larvae (hereafter "body surface area") was calculated by assuming the animal to be a cylindrical tube.
Organ Mass Analysis

Larvae, pupae, and adults were placed in a $-4^{\circ} \mathrm{C}$ freezer for $30 \mathrm{~min}$ for immobilization. An incision was made ventrally from the mouth to the anus. The midgut wall, midgut contents, silk glands, and cuticle were dissected free and their wet/dry mass recorded. The remainder of the carcass was weighed to the nearest milligram. Dry masses were obtained by placing the wet organs and carcass separately on labeled, preweighed weigh boats in a $65^{\circ} \mathrm{C}$ oven for $72 \mathrm{~h}$ (a pilot study determined full tissue desiccation within $48 \mathrm{~h}$ ). Total dry mass was calculated by adding the component dry masses (midgut wall, midgut contents, silk glands, cuticle, and the remaining carcass).

\section{Mitochondrial Extraction and Cytochrome c Oxidase Concentration}

Mitochondria were isolated from whole-animal larvae and pupae with a BioChain (Hayward, CA) Mitochondria Isolation Kit for Tissue (catalog no. KC010100). Each animal was weighed and washed twice with $10 \mathrm{~mL}$ of phosphate buffer solution. Each determination was based on analysis of $150 \mathrm{mg}$ of whole-body tissue from developmental groups L-I through adult. For smaller larval instars, individual larvae were combined to create the required 150-mg tissue sample. Three to seven determinations were typically made for each developmental stage. Tissues were minced with a razor blade inside glass petri dishes surrounded by crushed ice. Mitochondrial isolation buffer was added, and the solution was placed in a Dounce homogenizer surrounded by crushed ice. The tissue was homogenized for 35 strokes, and the homogenate was placed in a $15-\mathrm{mL}$ conical tube and centrifuged at $600 \mathrm{~g}$ for $10 \mathrm{~min}$ at $4^{\circ} \mathrm{C}$. The pellet was discarded, and the solution was recentrifuged until a clear supernatant was achieved. The supernatant was centrifuged at $12,000 \mathrm{~g}$ for $15 \mathrm{~min}$ at $4^{\circ} \mathrm{C}$. The pellet was collected and then resuspended in $50 \mu \mathrm{L}$ of mitochondrial isolation buffer. Then, $100 \mu \mathrm{L}$ of mitochondrial storage buffer and $50 \mu \mathrm{L}$ of dilution buffer were added to the sample.

Cytochrome c oxidase activity of isolated mitochondria was assessed with the BioChain Cytochrome c Oxidase Activity Assay Kit (catalog no. KC310100). Three trials were performed: a blank, a control, and the mitochondrial extract. Samples were placed in an enzyme dilution buffer and brought to $25^{\circ} \mathrm{C}$. Each cuvette contained $100 \mu \mathrm{L}$ of the sample and $850 \mu \mathrm{L}$ of the enzyme assay buffer. Baseline absorbance was then recorded. The reduced cytochrome c solution $(50 \mu \mathrm{L})$ was added to the cuvette and mixed by inversion, and absorption was read immediately and again at 5, 15, 25, 35, and 45 s. Activity was then calculated from rate of change in absorbance, dilution, and sample volume with BioChain's protocol. Cytochrome $c$ activity was expressed in units per gram of body mass, where 1 unit oxidizes $1 \mu \mathrm{M}$ of ferrocytochrome c per minute at $25^{\circ} \mathrm{C}$ and $\mathrm{pH} 7.0$. 


\section{Body Water Analysis}

For each developmental stage, 7-12 intact whole animals were weighed to the nearest milligram, placed on labeled, preweighed weighing boats, and then dehydrated for $72 \mathrm{~h}$ in a $65^{\circ} \mathrm{C}$ oven before reweighing. Body water composition was then calculated from the decrease in mass. Only larvae in the active feeding stage (i.e., not entering or exiting eclosion) were selected for weighing. Similarly, pupae in the middle of pupation and fully emerged adults were weighed.

\section{Lipid Content Determination}

For each developmental stage, a group of 7-10 silkworms was weighed to the nearest milligram, individually placed in $10-\mathrm{mL}$ glass test tubes, and dehydrated in a $65^{\circ} \mathrm{C}$ oven for $72 \mathrm{~h}$. Dehydrated animals were macerated with a glass tissue grinder, and the resultant material was incubated in $4 \mathrm{~mL}$ of 2-propanol at $70^{\circ} \mathrm{C}$ for $30 \mathrm{~min}$. Then, $2 \mathrm{~mL}$ of chloroform and $1 \mathrm{~mL}$ of distilled water were added to each tube and twice mixed with a vortex mixer for $2 \mathrm{~min}$. The tubes were tightly capped and held at room temperature for a period of $24 \mathrm{~h}$. They were then centrifuged at $21^{\circ} \mathrm{C}$ and $600 \mathrm{rpm}$ for $12 \mathrm{~min}$. The supernatant was collected, washed with $\mathrm{KCl}$, and mixed three times with a vortex mixer. The contents of the tubes were allowed to separate into layers, and the bottom layer was collected, placed in a preweighed glass vial, and held at room temperature overnight. After chloroform evaporation under a stream of nitrogen gas, the remaining lipids were weighed to the nearest milligram.

\section{Respirometry}

Closed-system respirometry was utilized to measure both $\dot{\mathrm{V}}_{2}$ and $\dot{\mathrm{V}}_{\mathrm{CO}_{2}}$ during the entire life cycle of $\mathrm{B}$. mori. All measurements were made $\sim 12 \mathrm{~h}$ after feeding to minimize variability in $\dot{\mathrm{V}}_{2}$ resulting from specific dynamic action. Hormonal activity has been linked to the light-dark cycle in silkworms (Fugo et al. 1984), and changes in light and/or dark have also been shown to alter $\dot{\mathrm{V}}_{2}$ and heart rate and/or cause heart rate reversals in other insect species (Stusek et al. 2000; Uchimura et al. 2005). Therefore, all of the incubators, holding chambers, and respirometers were transparent to admit ambient light, and all measurements were made during daylight hours to control for normal circadian rhythms.

Measurements of $\dot{\mathrm{V}}_{2}$ and $\dot{\mathrm{V}}_{\mathrm{CO}_{2}}$ were performed daily on larvae and pupae preweighed to the nearest milligram. Respirometers were constructed from transparent glass syringes of known volume that depended on the size of the larvae placed within them. The variables for oxygen consumption measurements varied, depending on the body mass of the developing insect. The time periods for measurements ranged from $15 \mathrm{~min}$ in L-V to $180 \mathrm{~min}$ in L-I. The initial syringe volume (minus body mass) ranged from $0.5 \mathrm{~mL}$ for L-I to $50 \mathrm{~mL}$ for PP. Twenty-gauge needles were fastened securely onto each syringe and inserted into a rubber stopper. Sealed syringes were then gently placed in a water bath maintained at $25^{\circ} \pm 0.5^{\circ} \mathrm{C}$.
Larvae of a specific stage were selected at random for measurements each day from a population of approximately 5001,000 larvae. Larvae retrieved from the incubator were placed in the gas-tight respirometers for $30 \mathrm{~min}$ to ensure that larvae were in a quiescent state and maintaining a standard metabolic rate before baseline $\dot{\mathrm{V}}_{2}$ measurement. The same protocol was used for $\dot{\mathrm{V}}_{2}$ measurements on a different group of larvae. The respirometer was refreshed with air at $25^{\circ} \pm 0.5^{\circ} \mathrm{C}$ between each measurement. Larvae were periodically viewed during the holding and measurement period to confirm their inactivity. Data from any respirometer containing physically active larvae were discarded. Individual larvae were measured three times each day, and mean $\dot{\mathrm{V}}_{2}$ or $\dot{\mathrm{V}} \mathrm{CO}_{2}$ was calculated for each larva. To measure $\mathrm{PO}_{2}$ in the respirometer, a measured volume of gas $(\sim 0.5 \mathrm{~mL})$ was injected directly from the syringe containing the animal into $\mathrm{O}_{2}$ or $\mathrm{CO}_{2}$ analyzers (see below) at specified time periods, as indicated for various life stages.

For determining gender-based $\dot{\mathrm{V}}_{2}$ differences, newly hatched L-I were placed in individual labeled petri dishes, where they remained separated for the rest of their life cycle. The $\dot{\mathrm{V}}_{2}$ measurements, as described above, were made throughout each instar as well as the pupal stage. Instar-V larvae and pupae were examined, and morphological characteristics were recorded. Gender was confirmed when the adults emerged after pupation. A small proportion of the silkworms died before gender could be determined, and data from these insects were discarded. Adult males were not separated from females in this study.

\section{Oxygen Consumption Measurements}

Oxygen levels in $0.5-\mathrm{mL}$ gas samples from the respirometers were measured with a thermostatted Clark-type oxygen electrode (Radiometer Model PHM 72 Mk-2, Copenhagen). The electrode was calibrated with a two-point calibration using humidified atmospheric air and nitrogen before each experiment and after each measurement period throughout the day. Oxygen consumption in the respirometer caused a decrease in $\mathrm{PO}_{2}$ of no more than $10.0 \mathrm{mmHg}(1.33 \mathrm{kPa})$ during measurements. Oxygen consumption, expressed as either $\mathrm{mL} \mathrm{O}_{2} \mathrm{~h}^{-1}$ or $\mathrm{mL} \mathrm{O}_{2}$ $\mathrm{g}^{-1} \mathrm{~h}^{-1}$, was calculated with conventional closed-respirometry calculations based on the $\mathrm{PO}_{2}$ change in the syringe, syringe volume (after correction for animal volume), elapsed time, and total body mass. Mean \pm 1 standard error (SEM) was calculated for body mass and mass-specific $\dot{\mathrm{V}}_{2}$ as a function of developmental stage. The combinations of syringe volume, elapsed time, gas volume, and gas injected from the syringe for measurement at each stage varied, depending on the body mass of the animal.

\section{Carbon Dioxide Production Measurements}

The $\dot{\mathrm{V}}_{2}$ was measured for each instar with the respirometry techniques described above for $\dot{\mathrm{V}}_{2}$. Larvae were randomly selected from a population of approximately 500-1,000 silkworms at the median age of each developmental stage. After 
completion of the experimental protocol outlined above for determining $\dot{\mathrm{V}}_{2}$, approximately $0.5 \mathrm{~mL}$ of gas from the respirometer was injected into a Medical Gas Analyzer (Beckman Model LB-2, Anaheim, CA). Carbon dioxide production ( $\mathrm{mL}$ $\mathrm{CO}_{2} \mathrm{~h}^{-1}$ and $\mathrm{mL} \mathrm{CO}_{2} \mathrm{~g}^{-1} \mathrm{~h}^{-1}$ ) was calculated as described above for $\dot{\mathrm{V}}_{2}$. Mean \pm 1 SEM was calculated for each developmental stage. Respiratory exchange ratios (REs) were calculated for each instar by dividing the mean $\dot{\mathrm{V}}_{\mathrm{CO}_{2}}$ by the mean $\dot{\mathrm{V}}_{\mathrm{O}_{2}}$ for each developmental stage.

\section{Analyses and Statistics}

Morphometrics. A regression analysis with 95\% confidence intervals was performed on the mean CSAs as a function of body mass. A $t$-test for slopes determined whether the resulting slope was significantly different from 0 . Independent $t$-tests were performed between the mean surface areas of cross sections 1-2 and 6-7 for the total-body cross section and the midgut-wall cross section for each developmental stage.

A one-way ANOVA and a Student-Newman-Keuls (SNK) analysis were performed on the following mean values as a function of developmental stage: total-body CSA, midgut-wall CSA, and the ratio of the latter to the former by developmental stage. Also analyzed in this manner were the gross morphological data of the cuticle, silk gland, and midgut-wall mass, body water content, total fat of wet/dry body mass, and cytochrome c oxidase activity. Means \pm 1 SEM are reported. An $\alpha$ level of 0.05 was adopted for all statistical decisions.

Metabolic Measurements. As a first approach, the $\dot{\mathrm{V}}_{2}$ of larvae, pupae, and adults were purposely grouped together and analyzed using simple nonlinear least squares regression models on semilogarithmic plots (see Glazier 2005). Separate analyses could be done by instar type (e.g., "larvae" as a grouping), but there are very large differences in the physiology even within different larval instars, and our purpose was initially to look across all of ontogeny. Subsequently, data were analyzed within instars.

Graphs were transformed to double-logarithmic axes to reveal linear relationships. Simple linear regressions were performed on the data sets (both whole-animal and mass-specific $\dot{\mathrm{V}}_{2}$ ) to determine scaling coefficients. Statistical significance was based on $\alpha=0.05$. A Shapiro-Wilk normality test determined the normality of the data. A one-way ANOVA determined whether the means were different from one life-cycle stage to another for both whole-animal and mass-specific $\dot{\mathrm{V}}_{2}$. An SNK test was utilized to compare all pairwise combinations of means. Slopes (allometric coefficients) of each instar were compared via $t$ distribution to the overall slope during development. A simple linear regression was performed on the mean values of $\dot{\mathrm{V}}_{2}$ as a function of body mass, and the slopes were calculated. Then, $t$-tests were calculated for comparison of slopes of the mean values of $\dot{\mathrm{V}}_{2}$ as a function of body mass by instar to the overall slope during development, employing an $\alpha$ of 0.01 instead of 0.05 to compensate for the repeated $t$ tests. An independent $t$-test was performed on each instar be- tween genders to determine whether there was a significant difference in either mean whole-organism or mass-specific $\dot{\mathrm{V}}_{2}$.

A simple linear regression was performed on the $\dot{\mathrm{V}} \mathrm{CO}_{2}$ data on double-logarithmic axes to determine slopes. A one-way ANOVA was performed on the $\dot{\mathrm{V}}_{\mathrm{CO}_{2}}$ data by stage, and an SNK test was utilized to compare all pairwise combinations of means.

\section{Results}

\section{Body Mass Changes during Development}

Body mass of Bombyx mori increased significantly, from a mean of $0.45 \pm 0.24 \mathrm{mg}$ in L-I to a zenith of $1.84 \pm 0.10 \mathrm{~g}$ in PP. From a peak for PP, body mass decreased to a mean of $0.79 \pm 0.30 \mathrm{~g}$ in pupae and $0.38 \pm 0.03 \mathrm{~g}$ in adults (Fig. 1; Table 1).

\section{Body Surface and Gut Cross-Sectional Areas}

Mean total-body surface area of larvae, using the average of diameters measured at body segments 1-2 and 6-7, increased $\sim 420$-fold, from $3.6 \mathrm{~mm}^{2}$ in L-I to $1,523.9 \mathrm{~mm}^{2}$ in PP, and showed a strong correlation with body mass (Fig. 2). The surface area-to-body mass ratio declined dramatically, from 9,046 $\mathrm{mm}^{2} \mathrm{~g}^{-1}$ in L-I to $699 \mathrm{~mm}^{2} \mathrm{~g}^{-1}$ in PP.

Mean whole-body CSA ranged from $0.11 \pm 0.01 \mathrm{~mm}^{2}$ for LI to $45.0 \pm 1.10 \mathrm{~mm}^{2}$ in PP (Fig. $3 A$ ). An SNK analysis separated the mean CSAs into three statistically significant groupings: (1) L-I-L-III; (2) L-IV, L-V; and (3) PP.

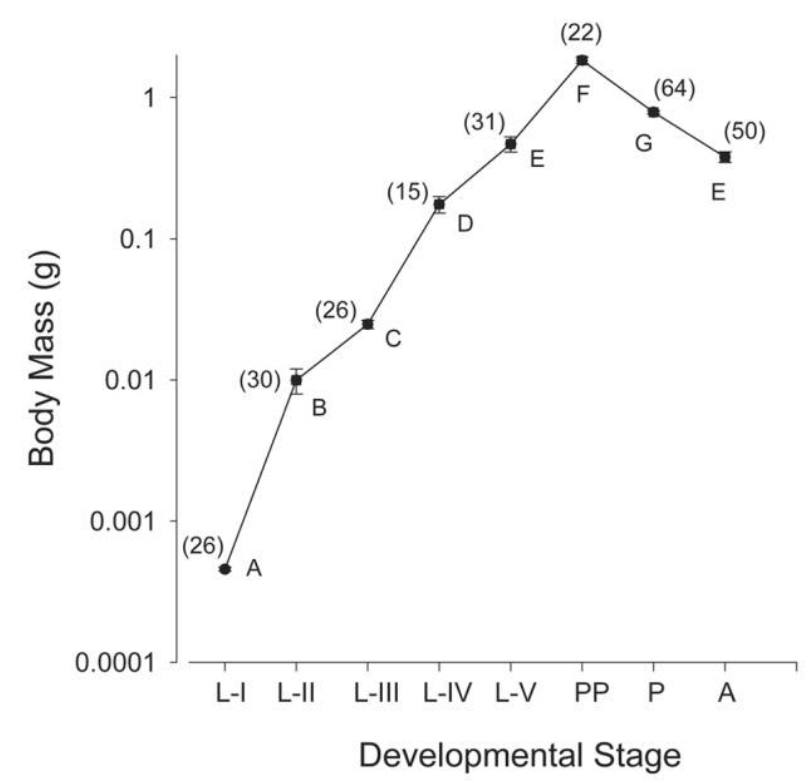

Figure 1. Body mass of developing Bombyx mori as a function of developmental stage from first-instar larvae through adults. Mean \pm SEM and $n$ (in parentheses) are indicated for each developmental stage. Letters distinguish Student-Newman-Keuls groupings. Developmental-stage abbreviations for all figures: L-I-L-V = larval instars I-V, PP = prepupae, $\mathrm{P}=$ pupae, and $\mathrm{A}=$ adults. 
Table 1: Whole-body and organ mass in larval (L, with stage indicated) and prepupal (PP) Bombyx mori

\begin{tabular}{|c|c|c|c|c|}
\hline \multirow[b]{2}{*}{ Mass Variable } & \multicolumn{4}{|c|}{ Developmental Stage } \\
\hline & L-III $(n=10)$ & $\mathrm{L}-\mathrm{IV}(n=10)$ & $\mathrm{L}-\mathrm{V}(n=11)$ & $\mathrm{PP}(n=10)$ \\
\hline \multicolumn{5}{|l|}{ Whole body: } \\
\hline Wet mass (mg) & $283 \pm 49$ & $584 \pm 40$ & $970 \pm 28$ & $1590 \pm 220$ \\
\hline Dry mass (mg) & $60 \pm 7$ & $118 \pm 13$ & $239 \pm 17$ & $373 \pm 43$ \\
\hline \multicolumn{5}{|l|}{ Cuticle: } \\
\hline Wet mass (mg) & $98 \pm 17$ & $221 \pm 26$ & $322 \pm 18$ & $329 \pm 82$ \\
\hline$\%$ of wet body mass & $34.8 \pm 1.3$ & $36.7 \pm 2.3$ & $33.1 \pm 1.3$ & $20.9 \pm 1.7$ \\
\hline Dry mass (mg) & $27 \pm 3$ & $40 \pm 4$ & $60 \pm 4$ & $72 \pm 6$ \\
\hline$\%$ of dry body mass & $44.2 \pm 4.1$ & $34.3 \pm 1.3$ & $25.43 \pm 2.8$ & $19.3 \pm 1.0$ \\
\hline \multicolumn{5}{|l|}{ Silk gland: } \\
\hline Wet mass (mg) & $3 \pm 1$ & $7 \pm 2$ & $20 \pm 3$ & $185 \pm 14$ \\
\hline$\%$ of wet body mass & $1.1 \pm .2$ & $1.1 \pm .3$ & $2.1 \pm .3$ & $11.6 \pm .7$ \\
\hline Dry mass (mg) & $1 \pm 1$ & $3 \pm 1$ & $3 \pm 1$ & $72 \pm 13$ \\
\hline$\%$ of dry body mass & $.74 \pm .15$ & $2.62 \pm .50$ & $1.29 \pm .24$ & $19.10 \pm .02$ \\
\hline \multicolumn{5}{|l|}{ Midgut: } \\
\hline Wet mass (mg) & $31 \pm 9$ & $95 \pm 12$ & $139.0 \pm .013$ & $450 \pm 94$ \\
\hline$\%$ of wet body mass & $11.00 \pm 1.50$ & $16.20 \pm 1.59$ & $14.22 \pm 1.23$ & $25.77 \pm 2.58$ \\
\hline Dry mass (mg) & $6 \pm 2$ & $17 \pm 2$ & $20 \pm 2$ & $63 \pm 6$ \\
\hline$\%$ of dry body mass & $9.9 \pm 1.3$ & $14.0 \pm 1.4$ & $8.5 \pm .5$ & $16.7 \pm 1.4$ \\
\hline
\end{tabular}

Note. Mean \pm 1 SEM.

Average mean midgut-wall CSA ranged from $0.030 \pm 0.010$ $\mathrm{mm}^{2}$ for L-I to $2.0 \pm 0.2 \mathrm{~mm}^{2}$ in PP (Fig. $3 B$ ). An SNK test separated the means into two statistically significant groupings: (1) L-I-L-III and (2) L-IV, L-V, and PP. Mean midgut-wall CSAs of body segments 1-2 and 6-7 were not significantly different for any stage (independent $t$-test), suggesting, as for whole-body CSA, that gut growth was by elongation rather than differential diameter increase along the length of the larva.

Midgut-wall CSA, expressed as a percent of whole-body CSA, showed a slight decline, from $17 \%$ to $11.5 \%$, in the first three instars and a recovery to $16.5 \%$ in L-IV, followed by a final sharp decline to $2.5 \%$ by the PP stage (Fig. $3 C$ ).

\section{Organ Mass}

Cuticle mass as a percentage of total body mass (wet and dry) was highest in L-III, falling sharply in PP (Fig. 4A, 4B; Table 1). An SNK analysis for wet mass separated the mean developmental stages into two statistically significant groupings: (1) L-III-L-V and (2) PP. An SNK analysis for cuticle dry mass separated the mean developmental stages into two statistically significant groups: (1) L-III, L-IV and (2) L-V, PP.

Not surprisingly, the body's proportion of silk gland mass rose sharply in late development, reaching a zenith in the PP stage, when the silk gland must become functional (Fig. $4 C$, $4 D$; Table 1). An SNK analysis for wet mass separated the mean developmental stages into two statistically significant groupings: (1) L-III-L-V and (2) PP. An SNK analysis for silk gland dry mass separated the mean developmental stages into two statistically significant groups: (1) L-III-L-V and (2) PP.
Midgut-wall mass. as a mean percentage of total-body mass, increased during development (Fig. 4E, 4F; Table 1). An SNK analysis for wet mass separated the mean developmental stages into two statistically significant groups: (1) L-III, L-IV and (2) L-V, PP. An SNK analysis for midgut-wall dry mass separated the developmental stages into three statistically significant groups: (1) L-III, L-IV; (2) L-V; and (3) PP.

\section{Body Water Content}

Total body water, expressed as a percentage of total body mass, increased from $\sim 75 \%$ in L-I to a plateau of $\sim 85 \%$ in L-III-

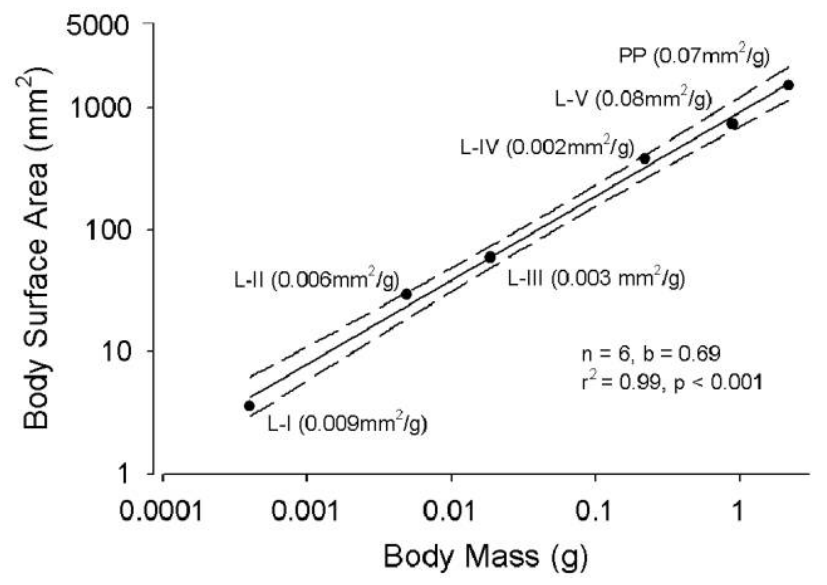

Figure 2. Mean total body surface area $( \pm$ SEM) as a function of body mass of developing Bombyx mori. The 95\% confidence intervals (dashed lines), slope $b$, and statistics are shown. 


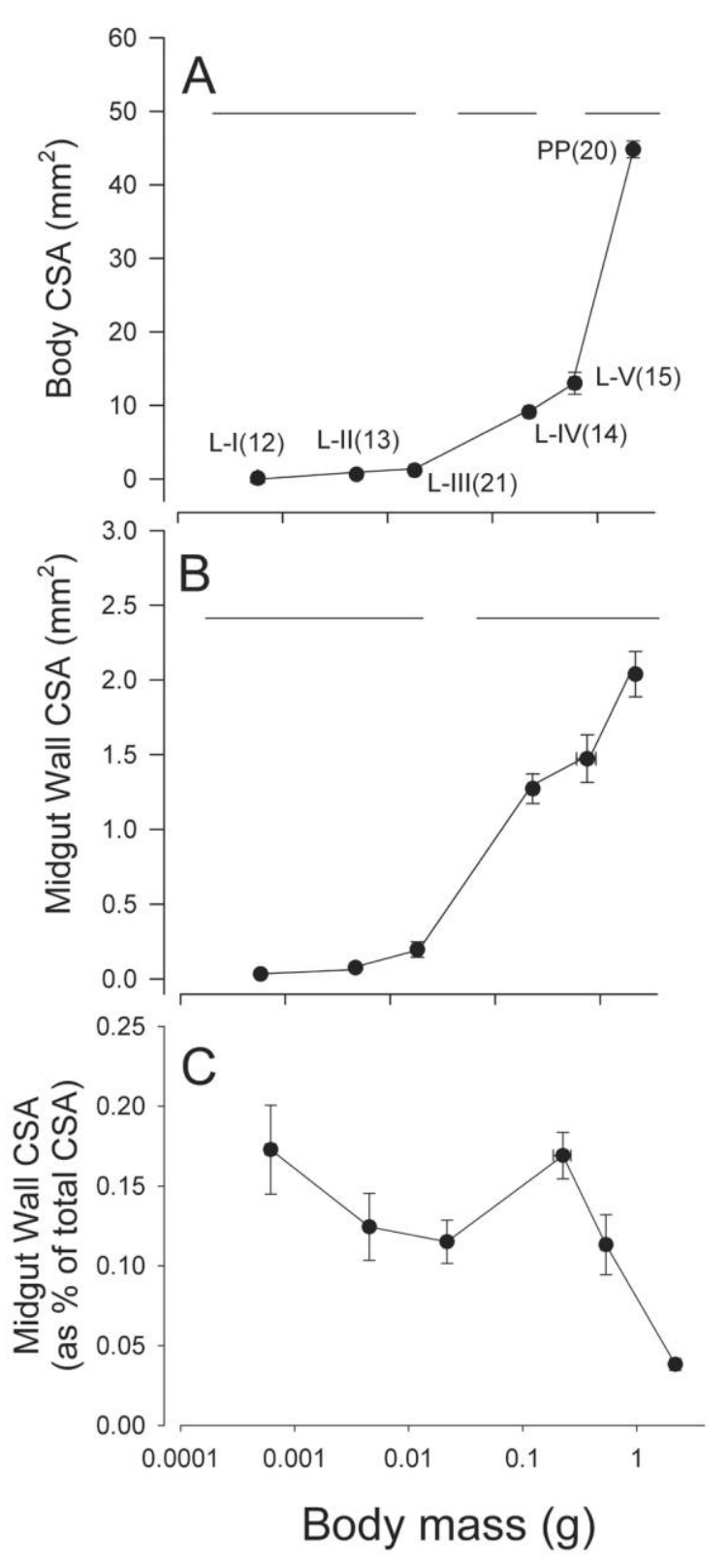

Figure 3. $A, B$, Cross-sectional area (CSA) of whole body $(A)$ and midgut wall $(B)$ of Bombyx mori as a function of body mass. Mean $\pm \mathrm{SEM}, n$ (in parentheses), Student-Newman-Keuls groupings (horizontal lines), and developmental stages are shown. $C$, Midgut-wall CSA as a percentage of body CSA as a function of body mass; $n$ values same as in $A$.

$\mathrm{L}-\mathrm{V}$, before falling sharply to a low of $\sim 67 \%$ in adult moths (Fig. 5A). An SNK analysis separated the mean developmental stages into three statistically significant groups: (1) L-I, pupae, and adults; (2) L-II-L-V; and (3) PP.

\section{Lipid Composition}

Body lipid, expressed as a percentage of total body wet mass, was $\sim 8.0 \%$ in early larval development but then fell sharply with further development before leveling off at $\sim 1.0 \%$ in L-IV and L-V. Lipid content then increased dramatically again, to a high of $\sim 10.0 \%$ in adults (Fig. $5 B$ ). An SNK analysis separated the mean developmental stages into three statistically significant groups: (1) L-I, adults; (2) L-II, L-III, PP, and pupae; and (3) L-IV, L-V.

Body lipid expressed as a percentage of total dry body mass ranged from $36.0 \% \pm 0.3 \%$ in L-I to $6.0 \% \pm 0.3 \%$ in L-V (Fig. $5 B)$. An SNK analysis separated the mean developmental stages into three statistically significant groups: (1) L-I, adults; (2) LII, L-III, PP, and pupae; and (3) L-IV, L-V.

\section{Cytochrome c Oxidase Activity}

Cytochrome c oxidase activity, an indicator of potential metabolic potential of the mitochondria, was highest in L-I, at $\sim 3$ units $\mathrm{g}^{-1}$, but then fell progressively to the lowest values of about $0.2-0.3$ units $\mathrm{g}^{-1}$ in PP, pupae, and adults (Fig. 6). Cytochrome c oxidase activity was separated into four statistically significant groups: (1) L-I-L-III; (2) L-IV; (3) L-V, pupae; and (4) PP, adults.

\section{Oxygen Consumption}

Whole-Animal $\dot{\mathrm{V}}_{2}$. Whole-animal $\dot{\mathrm{V}}_{2}$ was significantly correlated with body mass within each developmental stage, with the exception of the extremes of development: L-I, pupae, and adults. Mean whole-animal $\dot{\mathrm{V}}_{2}$ increased significantly $(P<0.001)$, from $0.00064 \pm 0.000047 \mathrm{~mL} \mathrm{O}_{2} \mathrm{~h}^{-1}$ in L-I to $0.77 \pm 0.06 \mathrm{~mL} \mathrm{O}_{2} \mathrm{~h}^{-1}$ in PP. Whole-animal $\dot{\mathrm{VO}}_{2}$ then decreased to $0.21 \pm 0.01 \mathrm{~mL} \mathrm{O}_{2}$ $\mathrm{h}^{-1}$ in pupae before rising slightly to $0.35 \pm 0.03 \mathrm{~mL} \mathrm{O}_{2} \mathrm{~h}^{-1}$ in adult females. Overall, these data are comparable to those reported for other insects (e.g., Tenney 1985; Bennett et al. 1999; Nespolo et al. 2003; Kemp et al. 2004).

Whole-animal $\dot{\mathrm{V}}_{2}$ on double-log plots is presented in Figure 7. Three analytical approaches were taken to determine the most effective way of representing data crossing multiple instars. First, simply using metabolic measurements from all individuals of all developmental stages pooled together yielded a value of $0.82\left(r^{2}=0.96, P<0.0001\right)$ for the exponent $b$ in the allometric equation (Fig. $7 A$; Table 2 ). A second approach used the mean $\dot{\mathrm{V}}_{2}$ values for each of the eight developmental stages and produced an overall relationship across ontogeny with an exponent $b$ of $0.83\left(r^{2}=0.99, P<0.0001\right.$; Fig. $\left.7 B\right)$. A $t$-test for slopes revealed no significant difference between the slopes generated using these two different approaches.

A final approach was to determine the slopes within each instar and then compare these values with the overall development-wide slope. Whole-animal $\dot{\mathrm{V}}_{2}$ was not correlated with body mass in L-I or pupae $(P>0.05$; Fig. $7 C)$. However, wholeanimal $\dot{\mathrm{V}}_{\mathrm{O}_{2}}$ increased significantly $(P<0.0001)$ as body mass increased within each instar from L-II through L-V, all of which had similar slopes ( $b=0.99,0.96,1.00$, and 1.02 , respectively). The PP had an even higher $b$ value of $1.49\left(P<0.001 ; r_{\text {adj }}^{2}=\right.$ 0.66). The slopes representing individual instars L-III and L-V and the pupae were not significantly $(P>0.10)$ different from the overall slope of 0.82 over all ontogeny. However, the slopes 

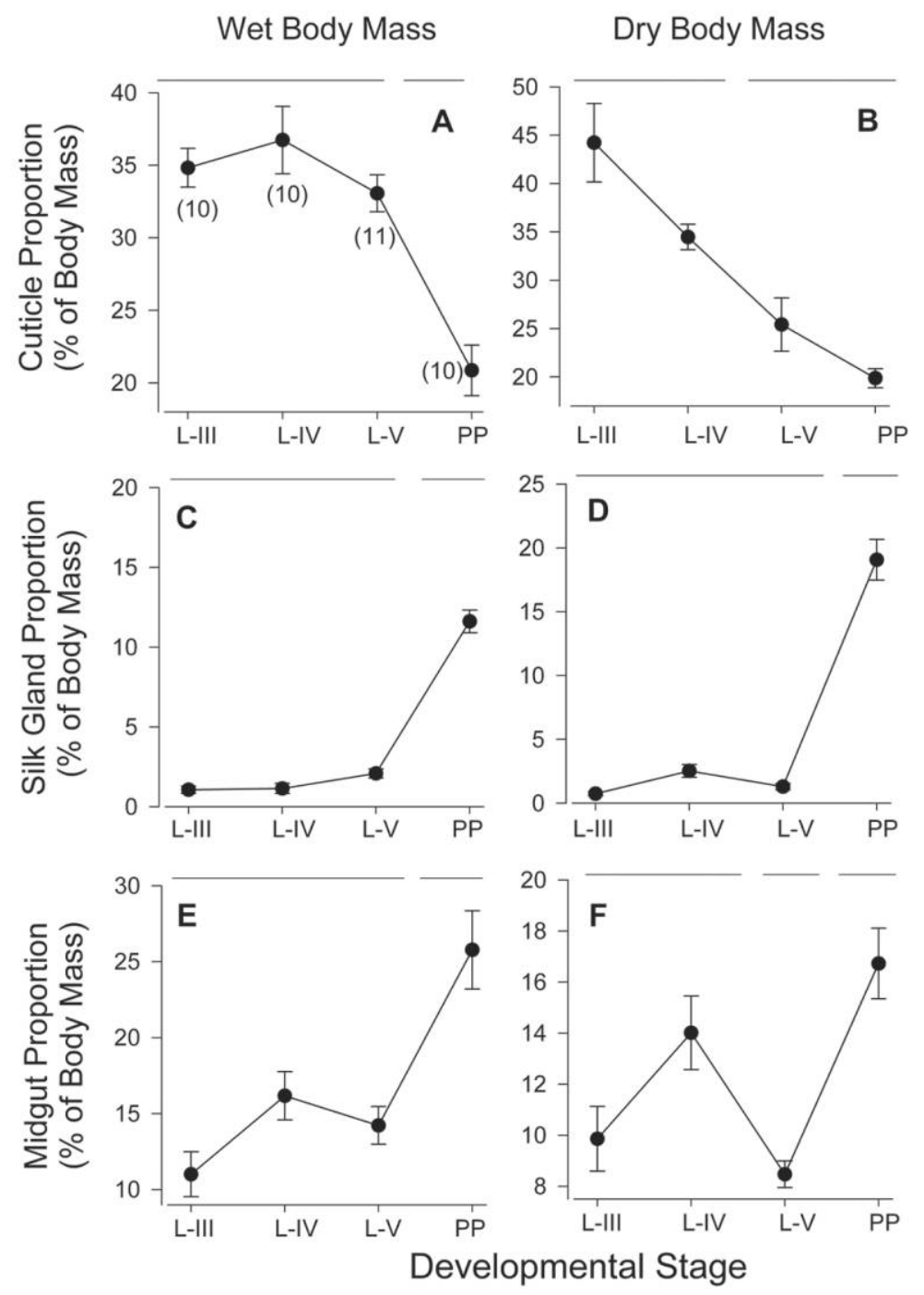

Figure 4. Organ mass proportion (as percentage of total body mass) for cuticle $(A, B)$, silk gland $(C, D)$, and midgut wall $(E, F)$ for developmental stages L-III-L-V, and PP of Bombyx mori; $n$ values in parentheses in $A$ apply to all plots. Mean ( \pm SEM) values are shown. Student-NewmanKeuls groupings are shown by horizontal lines at the top of each panel.

of L-II $(P<0.002)$, L-IV $(P<0.001)$, and PP $(P<0.001)$ were significantly different from the overall development-wide slope of 0.82 .

Mass-Specific Oxygen $\dot{\mathrm{V}}_{2}$. Log-log plots of all mass-specific $\dot{\mathrm{V}}_{2}$ data pooled from all developmental stages yielded a slope of $-0.18\left(r^{2}=0.54 ; P<0.0001\right.$; Fig. $\left.8 A\right)$. After separation of data by developmental stage, mean mass-specific $\dot{\mathrm{V}}_{2}$ by stage decreased by approximately four-fifths over development, from a mean of $1.38 \pm 0.12 \mathrm{~mL} \mathrm{O}_{2} \mathrm{~g}^{-1} \mathrm{~h}^{-1}$ in smallest L-I stages down to $0.28 \pm 0.02 \mathrm{~mL} \mathrm{O}_{2} \mathrm{~g}^{-1} \mathrm{~h}^{-1}$ in the heaviest stage (pupa), before rising again in the lighter adults. An SNK analysis separated the mass-specific $\dot{\mathrm{V}}_{2}$ means in Figure $8 B$ into five statistically significant groupings $(P<0.001)$ : (1) L-I-L-III; $(2) \mathrm{L}-$ II-L-IV; (3) L-V, PP; (4) pupae; and (5) adults. A simple linear-regression analysis on mean mass-specific $\dot{\mathrm{V}}_{\mathrm{O}_{2}}$ for each stage as a function of body mass (Fig. $8 B$ ) then yielded a slope of $-0.17\left(r^{2}=0.54\right)$, which was not significantly different $(P>0.10)$ from that determined from all pooled data. Finally, mass-specific $\dot{\mathrm{V}}_{2}$ plotted on double-logarithmic plots revealed no significant relationship $(P>0.10)$ between mass-specific $\dot{\mathrm{V}}_{2}$ and body mass for any single stage (Fig. $8 C$ ).

Body Surface Area and $\dot{\mathrm{V}}_{2}$. Mean whole-animal $\dot{\mathrm{V}}_{2}$ as a function of the body surface area showed an approximately isometric relationship $(b=1.1)$, with a relatively high $r^{2}$ value of 0.87 (Fig. 9A; Table 2). However, there was no significant relationship between mass-specific $\dot{\mathrm{V}}_{2}$ and body surface area $\left(r^{2}=0.58, P>0.05\right.$; Fig. 9B; Table 2).

Gender and $\dot{\mathrm{V}}_{2}$. Gender had no significant effect on either whole-animal or mass-specific $\dot{\mathrm{V}}_{2}$ in any of the larval instar groups. However, PP females had significantly higher wholeanimal mean $\dot{\mathrm{V}}_{2}\left(1.85 \pm 0.28 \mathrm{~mL} \mathrm{O}_{2} \mathrm{~h}^{-1}, n=7\right)$ than $\mathrm{PP}$ 

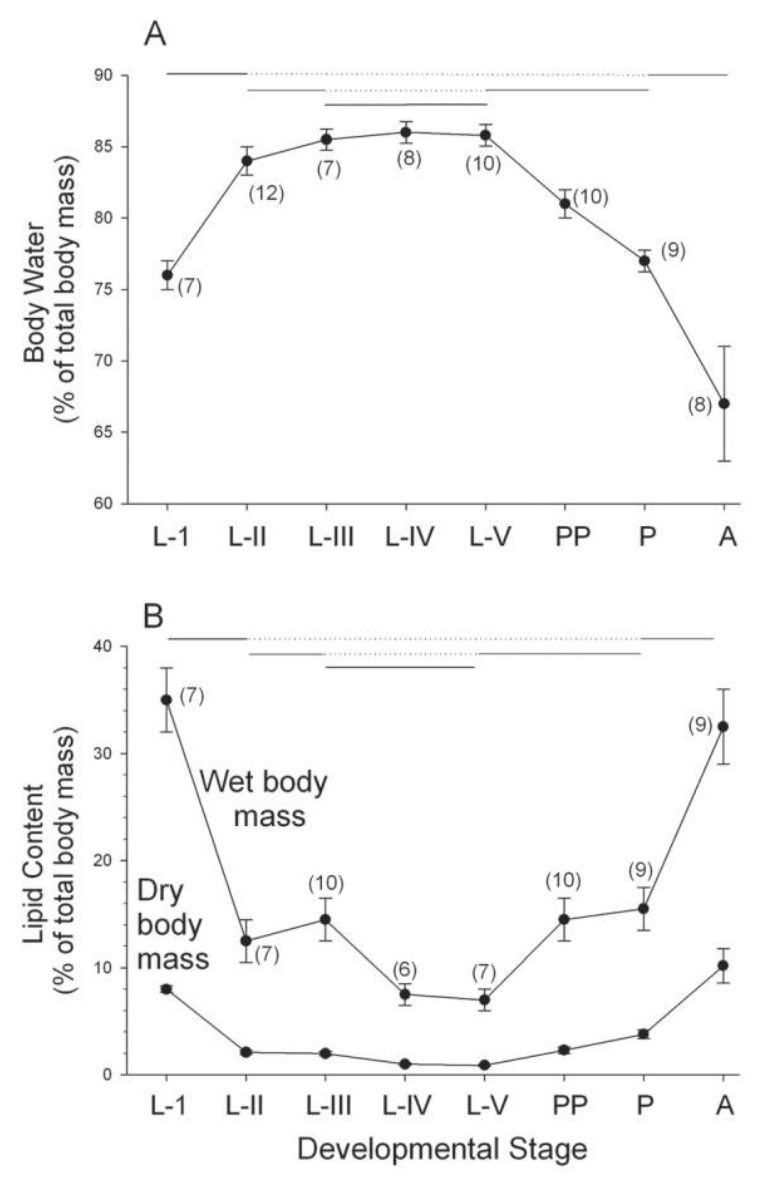

Figure 5. Body water $(A)$ and lipid contents $(B)$ as percentage of total body mass in Bombyx mori, as a function of developmental stage. Mean \pm SEM and $n$ values (in parentheses) are shown; for $B$, the $n$ values apply to both plots. Student-Newman-Keuls groupings are indicated by horizontal lines at the top of each panel.

males $\left(1.13 \pm 0.15 \mathrm{~mL} \mathrm{O}_{2} \mathrm{~h}^{-1}, n=8 ; P<0.05\right)$. Notably, PP females were significantly larger in body mass $(2.70 \pm 0.08 \mathrm{~g})$ than the males of the same age $(2.27 \pm 0.04 \mathrm{~g} ; P<0.0001)$.

In adults, male moths exhibited a significantly higher $(P<$ $0.05)$ whole-animal $\left(0.86 \pm 0.19 \mathrm{~mL} \mathrm{O}_{2} \mathrm{~h}^{-1}\right)$ and mass-specific $\left(5.23 \pm 0.19 \mathrm{~mL} \mathrm{O}_{2} \mathrm{~g}^{-1} \mathrm{~h}^{-1}\right) \dot{\mathrm{V}}_{2}$ than female moths $(0.35 \pm$ $0.07 \mathrm{~mL} \mathrm{O}_{2} \mathrm{~h}^{-1}$ and $0.82 \pm 0.20 \mathrm{~mL} \mathrm{O}_{2} \mathrm{~g}^{-1} \mathrm{~h}^{-1}$, respectively). Visual observation during the $\dot{\mathrm{V}}_{2}$ measurements revealed that males exhibited trembling antennae and vigorous body shaking. Males are extraordinarily sensitive to the female pheromones (Syed et al. 2006), and their hyperactivity likely resulted from air in the respirometer bearing traces of pheromones from female moths housed in the same laboratory. In contrast, the females remained quiescent in the respirometers at all times. Thus, the difference in $\dot{\mathrm{V}}_{2}$ between male and female adults is likely due to the stimulation of pheromone receptors in male moths - that is, we likely measured standard $\dot{\mathrm{V}}_{2}$ in females but something nearing maximal $\dot{\mathrm{V}}_{2}$ in males. Interestingly, one male moth in our experiments exhibited a mass-specific $\dot{\mathrm{V}}_{2}$ of $15.12 \mathrm{~mL} \mathrm{O}_{2} \mathrm{~g}^{-1} \mathrm{~h}^{-1}$, which is $\sim 18$ times the average for females $\left(0.82 \mathrm{~mL} \mathrm{O}_{2} \mathrm{~g}^{-1} \mathrm{~h}^{-1}\right)$ and approaches the metabolic rate of a hovering hummingbird $\left(15.58 \mathrm{~mL} \mathrm{CO}_{2} \mathrm{~g}^{-1} \mathrm{~h}^{-1}\right.$; Powers and Conley 1994).

\section{Carbon Dioxide Production}

Whole-animal $\dot{\mathrm{V}}_{2}$ increased significantly (one-way ANOVA, $P<0.001)$ over most of development and then decreased in pupae and adults, in a pattern similar to $\dot{\mathrm{V}}_{2}$ (Fig. 10A). Mean whole-animal $\dot{\mathrm{V}}_{\mathrm{CO}_{2}}$ ranged from $0.01 \pm 0.0006 \mathrm{~mL} \mathrm{CO}_{2} \mathrm{~h}^{-1}$ in L-I to $0.62 \pm 0.07 \mathrm{~mL} \mathrm{CO}_{2} \mathrm{~h}^{-1}$ in PP. An SNK analysis separated the means into two statistically significant groupings: (1) L-IL-IV and (2) L-III-L-V, PP, pupae, adults.

Mean mass-specific $\dot{\mathrm{V}}_{\mathrm{CO}_{2}}$ decreased significantly $(P<0.001)$ over development (Fig. 11), ranging from $1.35 \pm 0.06 \mathrm{~mL} \mathrm{CO}_{2}$ $\mathrm{g}^{-1} \mathrm{~h}^{-1}$ in the L-I stage down to $0.24 \pm 0.03 \mathrm{~mL} \mathrm{CO}_{2} \mathrm{~g}^{-1} \mathrm{~h}^{-1}$ in pupae. The means separated into four statistically significant groupings: (1) L-I; (2) L-II, L-III, L-V, and PP; (3) L-II, L-IV, $\mathrm{PP}$, and adults; and (4) pupae. Mass-specific $\dot{\mathrm{V}}_{\mathrm{CO}_{2}}$, plotted as a function of body mass on a double-logarithmic plot, yielded an $r^{2}$ value of 0.76 and a slope of $0.52(P<0.0001$; Fig. $11 A)$. The mass-specific $\dot{\mathrm{V}} \mathrm{CO}_{2}$, plotted on a double-logarithmic plot (Fig. $11 B$ ), revealed an $r^{2}$ value of 0.46 and a slope of -0.14 $(P<0.0001)$.

As a final note on this topic, many insects exhibit discontinuous ventilation patterns resulting in pulsatile $\mathrm{CO}_{2}$ release (Levy and Schneiderman 1966; Hetz and Bradley 2005; Chown et al. 2006; Gray and Bradley 2006). The methodology of our study would not resolve transient changes in $\mathrm{CO}_{2}$ release.

\section{Respiratory Exchange Ratio}

In early development, L-I, L-II, L-III, and L-IV had REs of $1.10,0.57,0.77$ and 0.60 , respectively (Fig. 12). The RE value of 1.10 for L-I of B. mori suggests that these larvae are primarily metabolizing carbohydrates stored during embryogenesis (Kleiber 1975). A switch to fat metabolism during the next three

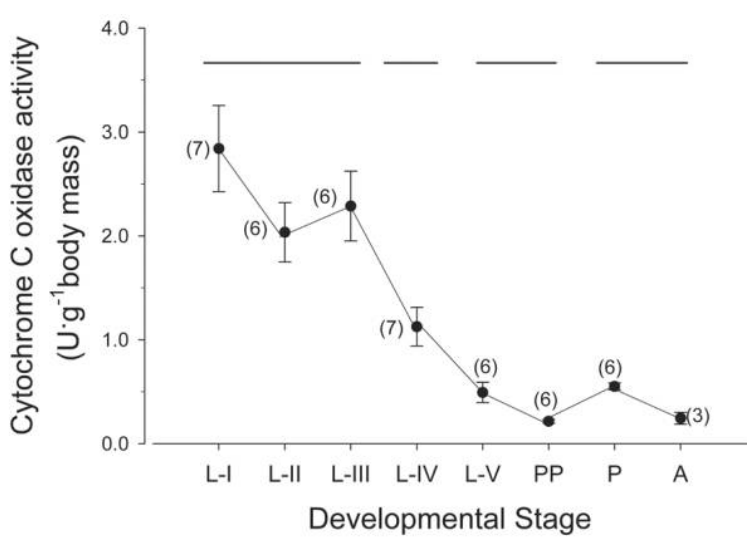

Figure 6. Cytochrome c oxidase activity as a function of developmental stage of Bombyx mori. Mean \pm SEM and $n$ values (in parentheses) are shown. Student-Newman-Keuls groupings are indicated by horizontal lines at the top of the panel. 


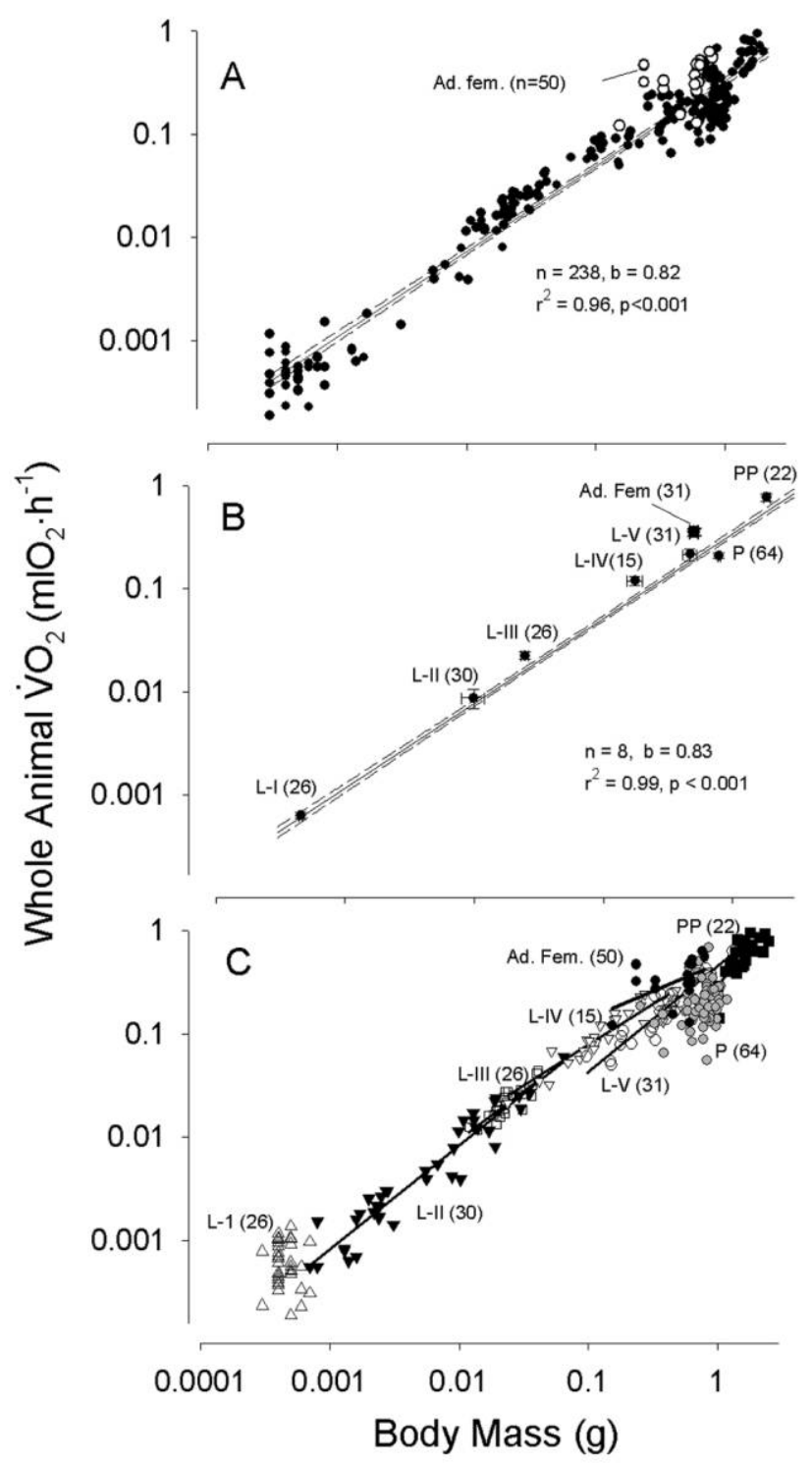

Figure 7. Alternative approaches to expressing allometric $\dot{\mathrm{V}}_{2}$ relationships in developing Bombyx mori. A shows a double-log plot of whole-animal $\dot{\mathrm{V}}_{2}$ as a function of body mass, including all data irrespective of stage. Adults (females only) are included but are distinguished by open symbols. In $B$, only mean $\dot{\mathrm{V}}_{2}$ values for each developmental stage are plotted, with the regression calculated on the basis of these means. $C$ differentiates whole-animal $\dot{\mathrm{V}}_{2}$ data for each stage throughout development. Significant simple linear regressions with adjusted regression coefficients, $95 \%$ confidence intervals (dashed lines), $n$ values, and $b$ values (allometric coefficients) are shown in $A$ and $B$. See text for individual $b$ values in $C$.

larval stages might be explained by the rising RE. However, this apparent transition might also be attributed to the 12 -h period of food deprivation before $\dot{\mathrm{V}}_{2}$ measurements rather than to any fundamental shift in energy metabolism. The REs in L-V and PP increased to 1.42 and 1.59 , respectively, which in insects can indicate lipogenesis (Kleiber 1975). During the PP stage, the insect has completed an intensive feeding stage and synthesizes fat stores for the remainder of its life cycle. The RE of
0.86 during metamorphosis in $B$. mori could be explained by protein metabolism or a mixture of carbohydrate and lipid metabolism. The RE decreased again to 0.86 in pupae and to 0.74 in adults. Metamorphosing pupae undergo histolysis and histogenesis simultaneously. The RE during this stage could be an indicator of the catabolism of all three nutrient sources.

\section{Discussion}

This study has generated data sets on morphological, metabolic, and biochemical changes throughout development and metamorphosis in Bombyx mori. It therefore provides the basis for examining some underlying mechanisms for the emergent pattern of intraspecific metabolic allometry and its analyses. In building toward a synthesis of these topics, a discussion will first be offered for each subcomponent of the study.

\section{Morphological and Biochemical Data}

Developmental Changes in Body Mass, Body Surface Area, and Cross-Sectional Area. Bombyx mori showed dramatic body mass gain through early larval stages, reaching a zenith in PP and then decreasing in pupae and adults. In some holometabolous insects, for example, silkworms, beetles, and flies, the PP stage is the final stage for food consumption because the adults, lacking functional mouth parts, exist only briefly to reproduce (Rockstein 1973; Ganga 2003). Once larvae of these insects enter metamorphosis, energy stored during the PP stage will be the sole source available for the remainder of the life cycle. Not surprisingly, then, once the insect reaches a maximum weight in the PP stage, the body mass decreases with age during a brief adulthood.

Total midgut-wall CSA increased absolutely throughout development in $B$. mori but actually decreased when expressed as a percentage of the body CSA, with the lowest values in the PP stage (Fig. 3C). Midgut-wall thickness reflects a combination of both smooth-muscle tissue, generating peristaltic mobilization of gut contents, and absorptive surface area facing the gut lumen. Older larvae of Manduca sexta exhibit increased effectiveness in digestion and absorption, compared to younger larvae (Chamberlin et al. 1997), and a similar increase in efficiency in B. mori could maintain digestive functions even as

Table 2: Slope $b$, the coefficient in the allometric equation for $\dot{\mathrm{V}}_{2}$, calculated using either body mass or surface area, in the silkworm Bombyx mori

\begin{tabular}{lccc}
\hline$X, Y$ & $b$ & $r^{2}$ & Significance \\
\hline Body mass: & & & \\
Whole-animal $\dot{\mathrm{V}}_{\mathrm{O}_{2}}$ & .82 & .96 & $<.0001$ \\
$\quad$ Mass-specific $\mathrm{V}_{\mathrm{O}_{2}}$ & -.17 & .54 & Not significant \\
Surface area: & & & \\
$\quad$ Whole-animal $\dot{\mathrm{V}}_{2}$ & 1.1 & .87 & $<.001$ \\
Mass-specific $\dot{\mathrm{V}}_{\mathrm{O}_{2}}$ & -.27 & .58 & Not significant \\
\hline
\end{tabular}

Note. $n=214$ for all groups. 


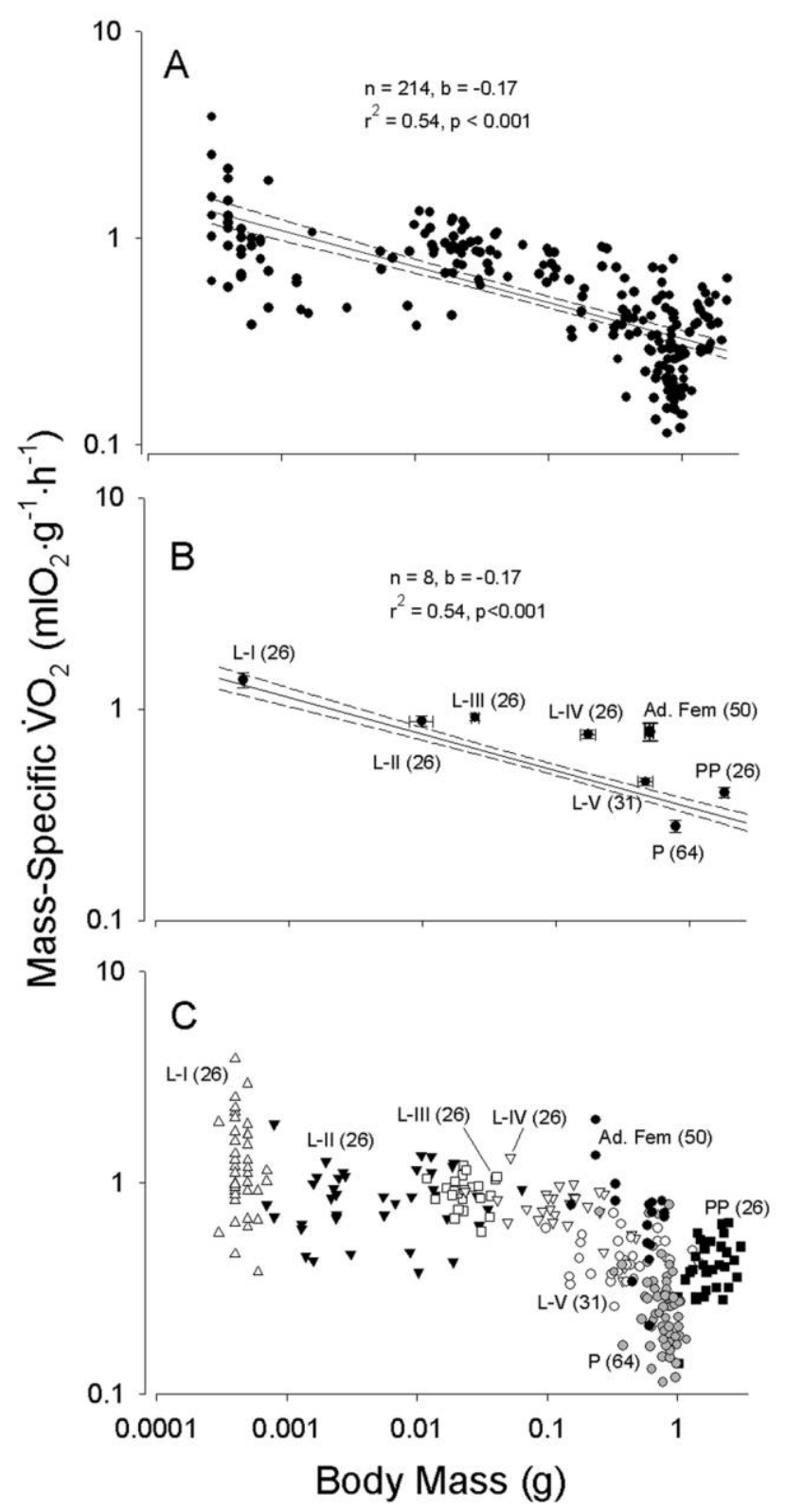

Figure 8. Mass-specific $\dot{\mathrm{V}}_{2}$ as a function of body mass across development in Bombyx mori. A shows a double-log plot, including all data irrespective of stage. $B$ indicates mean mass-specific $\dot{V}_{O_{2}}$ values for the means of each developmental stage. Linear regression with $95 \%$ confidence intervals (dashed lines), $b$ values (allometric coefficient), and statistics are shown in $A$ and $B . C$ differentiates mass-specific $\dot{V}_{2}$ data for each stage throughout development.

midgut-wall CSA — and presumably the surface area available for nutrient absorption-decreases.

Developmental Changes in Major-Organ Mass. One of the driving factors behind this study was to determine how the body proportions of major metabolism-intensive tissues in B. mori change during the dramatic growth and development of larval instars. Three specific tissues-midgut, silk glands, and cuticle-were singled out for examination.
The insect midgut is a highly metabolic organ with an epithelial layer rich in mitochondria, rough endoplasmic reticulum, and goblet cells involved in ion transport. The gut also has outer circular and longitudinal smooth-muscle layers (Mandel et al. 1980; Bradley 1984; Parenti et al. 1985; Baldwin and Hakim 1991; Gibellato and Chamberlin 1994; Jouni and Wells 1996; Grant 2006). Certainly, the gut is one of the dominant organs in larval B. mori, and it would seem likely that it makes a large contribution to total oxygen consumption. Yet earlier stages of the silkworm have the highest mass-specific $\dot{\mathrm{V}}_{2}$, while L-III larvae have the lowest body proportion of midgut. These data suggest that, at least in early development, the digestive activity of the midgut is not the major contributor to metabolic intensity. In metamorphosing insects, a surge of ecdysone occurs at the onset of the pupal stage, and mitochondria decrease in the Malpighian-tubule microvilli in response to this hormone and further decrease during metamorphosis (Bradley 1984). Therefore, the midgut wall might have a larger mass in the pupal stage than in earlier stages, but the onset of metamorphosis could cause the number of mi-

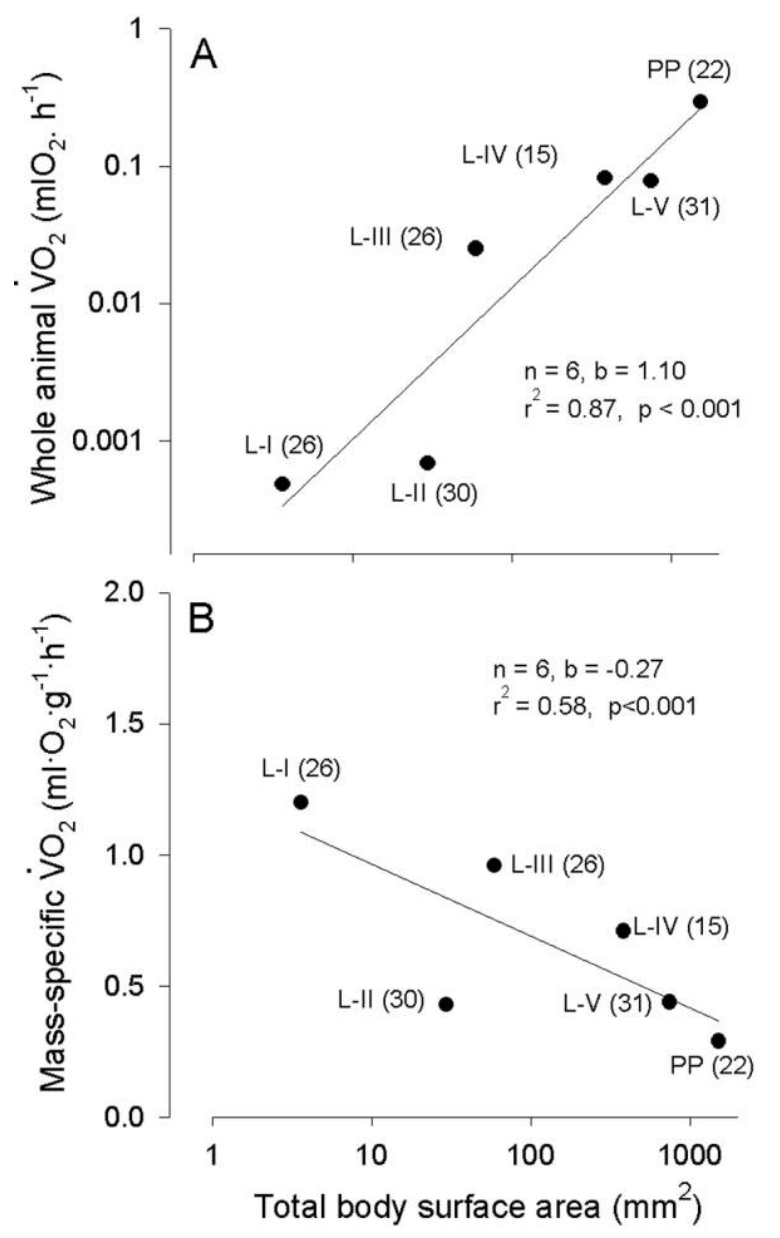

Figure 9. Relationship between surface area and whole-animal $(A)$ and mass-specific $(B) \dot{\mathrm{V}}_{\mathrm{O}_{2}}$ in Bombyx mori over development. Simple linear regressions with $b$ values and $n$ values (in parentheses) are shown. 


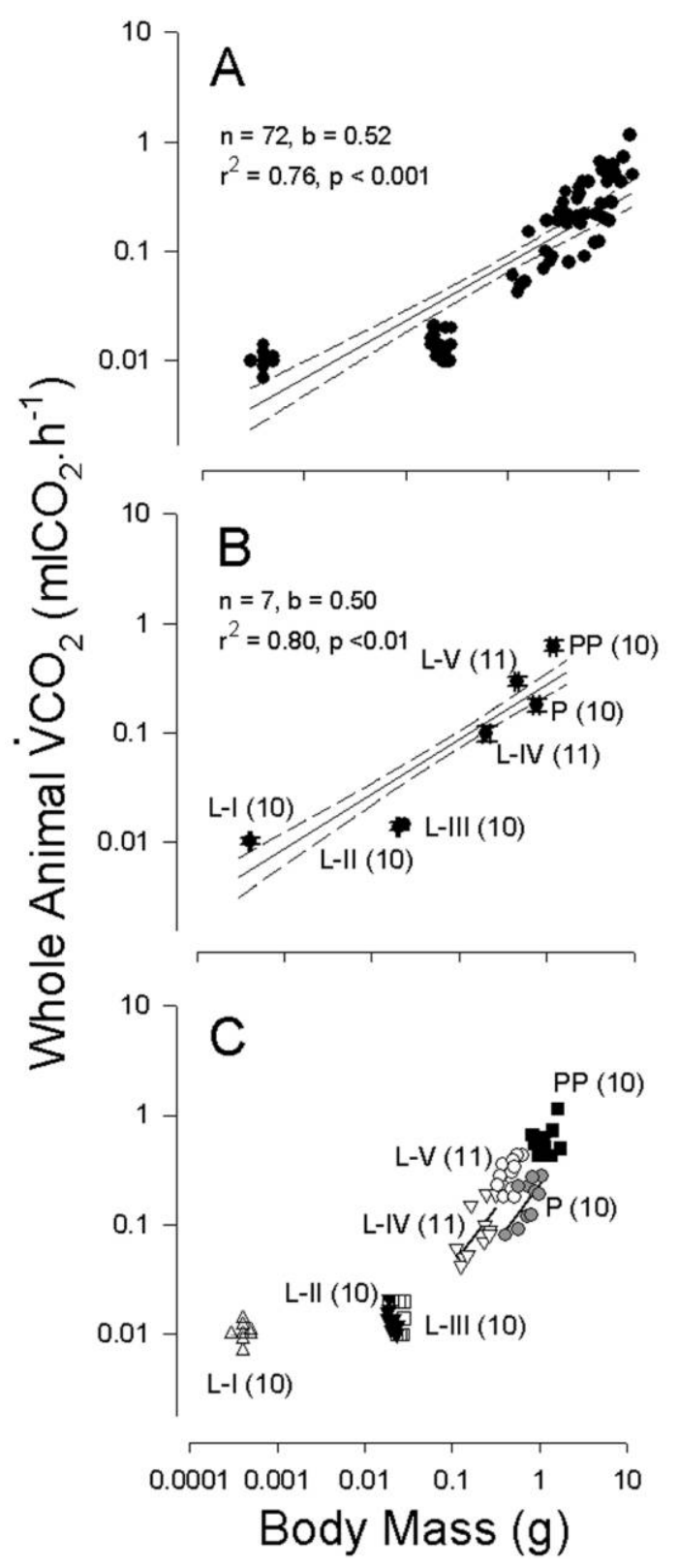

Figure 10. Alternative approaches to expressing allometric $\dot{\mathrm{V}}_{2}$ relationships in developing Bombyx mori. A shows a double-log plot of whole-animal $\mathrm{VCO}_{2}$ as a function of body mass, including all data irrespective of stage. In $B$, only mean $\dot{\mathrm{V}} \mathrm{CO}_{2}$ values for each developmental stage are plotted, with the regression calculated on the basis of these means. $C$ differentiates whole-animal $\dot{V}_{\mathrm{CO}_{2}}$ data for each stage throughout development. Significant simple linear regressions with adjusted regression coefficients, 95\% confidence intervals (dashed lines), $n$ values, and slopes (b) are shown in $A$ and $B$. See text for values of individual slopes in $C$.

tochondria to decrease and lower the metabolic activity of the tissue on a per-gram basis (Chamberlin 2007).

The silk glands of $B$. mori are another highly metabolically active tissue, because of the energy-dependent synthesis and secretion of silk proteins (Matsuura et al. 1968; Morimoto et al. 1968; Tashiro et al. 1968; Sasaki and Tashiro 1976). Silk glands rapidly reach their peak mass by the PP stage, are used to spin the cocoon at pupation, and then are rapidly catabolized during metamorphosis (Matsuura et al. 1968). The PP, with the lowest mass-specific $\dot{\mathrm{V}}_{2}$ across silkworm development, had the highest proportion of silk-gland mass to total body mass. Therefore, although the silk gland has high metabolic potential, silk glands are unlikely to be a major factor contributing to changes in mass-specific $\dot{\mathrm{V}}_{2}$ across development.

The stages with the highest proportion of cuticle also had the highest mass-specific $\dot{\mathrm{V}}_{2}$ (L-I-L-III). However, the cuticle

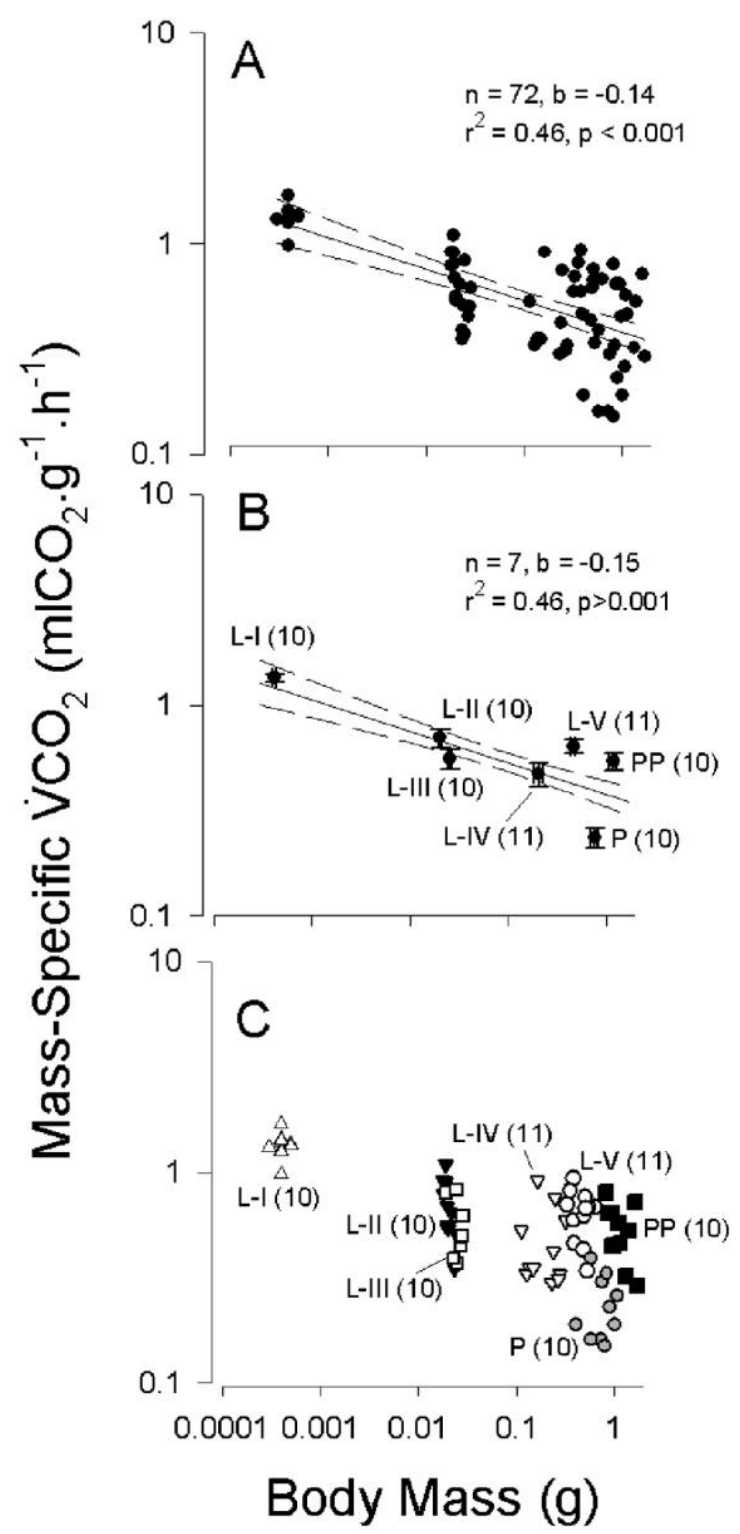

Figure 11. Mass-specific $\dot{\mathrm{V}} \mathrm{CO}_{2}$ as a function of body mass across development in Bombyx mori. A shows a double-log plot, including all data irrespective of stage. $B$ indicates mean mass-specific $\dot{\mathrm{V}} \mathrm{CO}_{2}$ values for each developmental stage. Linear regression with $95 \%$ confidence intervals (dashed lines), $b$ values (allometric coefficients), and statistics are shown in $A$ and $B$. $C$ differentiates mass-specific $\dot{\mathrm{V}} \mathrm{CO}_{2}$ data for each stage throughout development. 


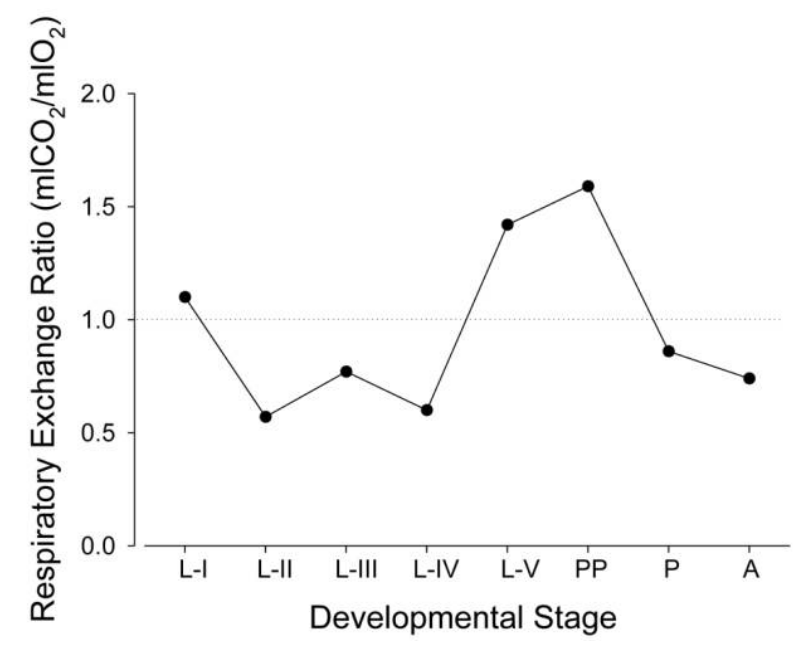

Figure 12. Respiratory exchange ratios as a function of developmental stage in Bombyx mori. Gray line indicates a value of 1.0, where $\dot{\mathrm{V}} \mathrm{CO}_{2}$ equals $\dot{\mathrm{V}} \mathrm{O}_{2}$.

has comparatively low metabolic potential, and it is doubtful that this organ is a factor contributing to changes in massspecific $\dot{\mathrm{V}}_{2}$ across development.

Developmental Changes in Water Composition. Water content displayed an inverted U-shaped relationship, with water content highest in mid-larval developmental stages and declining with pupation and metamorphosis (Fig. 5A). Larval B. mori receive water largely through their food, and the rate of feeding is low or nonexistent in both early larval and PP and pupal stages, when body water content is also low. However, the actual water content of tissues is a complex balance of water intake and water loss in feces and through tracheal gas exchange (see, e.g., Cloudsley-Thompson 1975; Lighton 1996; Chown et al. 2006). Of course, no feeding per se occurs in lepidopteran pupae, and there must accordingly be a significant net loss of water during this stage. The pupae are enclosed in a silk cocoon; however, the cocoon does not limit water loss from the pupae (Blossman-Myer and Burggren 2010). While changes in body water composition during development have been related to shifts in metabolic scaling, for example, in some altricial bird embryos, Glazier (2005) suggests that body water alone is unlikely to account primarily for such shifts, implicating instead changes in proportion of metabolically active tissue.

Developmental Changes in Lipid Composition. Overall, the lipid contents we report for $B$. mori are in the general range reported for a number of species of Lepidoptera (Domroese and Gilbert 1964; Fast 1964; Prasad et al. 1986). Lipid and sterol concentrations are highly dependent on diet content and nutritional levels, even within species (Satake et al. 2000; Connor et al. 2006), so reported differences in the literature could be related, in part, to animal husbandry as well as to fundamental interor intraspecific differences. Lipid content differences in the cecropia moth are gender dependent (Domroese and Gilbert
1964), with females having higher lipid contents than males. One might anticipate similar gender differences in adult B. mori, where all activities, including egg production and laying, are based strictly on fat stores laid down before pupation. In $M$. sexta, the size of the fat body itself increases dramatically before metamorphosis, but much of the increase in mass of the fat body is actually lipoprotein or other proteins used in adult tissue creation (Tojo et al. 1978; Prasad et al. 1986; Cağlayan 1990). The distribution of fat throughout the body as a function of developmental change would be an interesting area for future research.

During development in B. mori, the lowest lipid contents were in L-IV and L-V (Fig. 5B), where aggressive feeding and tissue growth are apparent. In the final days of $\mathrm{L}-\mathrm{V}$, a final push of fat storage is initiated, with fat stores increasing $\sim 10$ fold over those in mid-larval stages, presumably to facilitate metamorphosis during pupation. These fat stores are laid down in so-called fat bodies (Canavoso et al. 2004; Patel et al. 2005), where they are used as an energy source during pupation (Prasad et al. 1986) as well as for new cellular membranes and for the precursor materials of steroidal hormones (FernandoWarnakulasuriya et al. 1988).

There was a consistent inverse correlation between body water and lipid content throughout normal ontogeny (see Fig. 5). This inverse relationship has also been revealed through experimental diet and water intake manipulation in larval $M$. sexta (Ojeda-Avila et al. 2003). Numerous factors can affect the interrelationship between lipid and water content. Most obvious, perhaps, is that as lipid stores wax and wane, the water content on a mass-specific basis will likely change in the opposite direction, there simply being less "water-based" tissue in the overall body tissue makeup if large fat stores also are to exist as a necessary component of metamorphosis.

Developmental Changes in Cytochrome c Oxidase Activity. Cytochrome c oxidase activity is a highly accurate indicator of a tissue's metabolic potential (Davies and Moyes 2007). Massspecific cytochrome c oxidase activity decreases through development of the fly Lucilia illustris (D'Costa and Birt 1966), following a relationship similar to that of mass-specific oxygen consumption. The electron transport chain enzyme complexes (including cytochrome c oxidase) in the midgut of lepidopterans decline in activity throughout development, and the amount of cytochrome $\mathrm{c}$ oxidase activity declines as programmed cell death occurs during metamorphosis (Chamberlin 2007). In our study, the stages of $B$. mori with the highest massspecific cytochrome c oxidase activity levels, L-I-L-III (Fig. 6), also had the highest mass-specific oxygen consumption. The lowest activity levels per gram were in the PP and adult stages, which, not surprisingly, also had relatively low mass-specific oxygen consumption. These data implicate mitochondrial density changes during development as a significant factor in the measured metabolic rate changes from larval instars through metamorphosis to the adult. 
Intraspecific Allometry of $\dot{\mathrm{V}}_{2}$

Body Mass as Independent Variable. The general intraspecific pattern of change in $\dot{\mathrm{V}}_{2}$ during development in B. mori was generally similar to that predicted by interspecific comparisons: namely, increases in whole-animal $\mathrm{V}_{2}$ failed to keep pace with body mass increases. However, the value of 0.82 for the slope $b$ of whole-animal $\dot{\mathrm{V}}_{2}$ over the entire range of development was slightly higher than the predicted mass-specific slopes of $0.67-0.75$ based on interspecific studies. However, on an instarby-instar basis, slopes ranged from 0.96 to 1.49 within individual instars of silkworms (Fig. 7C), starkly different from the value obtained from pooling all data across development. Wieser (1984) has described a similar phenomenon for growing vertebrates.

What could account for within-instar $\dot{\mathrm{V}}_{2}$-body mass relationships that are either nonsignificant (L-I) or higher than 1.0 $(\mathrm{PP})$ ? Certainly, there are changes both within and between instars in terms of the individual's total percentage of metabolically active tissue (Fig. 4). There are also changes in the amount of proliferating imaginal tissues (Heyland and $\mathrm{Moroz}$ 2006), where increased mitotic activity may increase $\dot{V}_{\mathrm{O}_{2}}$ (Rockstein 1973). Finally, a rise in $\dot{\mathrm{VO}}_{2}$ during ecdysis has been reported for some insects (Edwards 1953; Rockstein 1973). Thus, a slope $\sim 1.0$ or greater between $\dot{\mathrm{V}}_{2}$ and body mass in certain larval B. mori might be attributed to the oldest, and consequently the largest, larvae within that stage preparing for and then undergoing ecdysis. Insects experience a surge of hyperplastic growth in the epidermal layers underlying the cuticle during ecdysis (Rockstein 1973). This mitotic surge requires extra energy to increase metabolism above normal resting standard metabolic rate and likely contributes to the increase in $\dot{\mathrm{V}}_{2}$ with increasing body mass in B. mori. Larvae increase feeding immediately before ecdysis, and increases in feeding cause up to fourfold increases in metabolic rate in woolly-bear caterpillars (Gynaephora groenlandica; Bennett et al. 1999).

Clearly, interspecific allometric values (e.g., 0.75) and perhaps even allometric principles (e.g., positive scaling of wholeanimal $\dot{\mathrm{V}}_{2}$ with increasing body mass) cannot be simply imported without question to help understand metabolic changes during development in B. mori or other similar insects. Additional complexity is rendered by a complex life cycle in which body mass actually decreases in late development, and, concurrently, the pupal phase had the lowest mass-specific $\dot{\mathrm{V}}_{\mathrm{O}_{2}}$ rates of all the developmental stages. During this period of metamorphosis, there is histolysis of the larval nervous tissue, epidermis, prothoracic glands, and parts of the digestive tract (Heyland and Moroz 2006). Simultaneously, adult morphological structures are synthesized, for example, tracheal muscles, eyes, wings, legs, genitalia, and the adult nervous system (Heyland and Moroz 2006). Given these radical morphological and presumably physiological changes, the emergence of complex scaling relationships with body mass is hardly surprising.

Body Surface Area as Independent Variable. Body surface area has often been identified as a potentially important factor that drives allometry for metabolic rate (for references, see SchmidtNielsen 1984; West et al. 2002). Discussions centered around surface area-to-volume ratios and their relationships to metabolic scaling typically evoke the need for endotherms to eliminate metabolically produced body heat. Of course, with the possible exception of males stimulated to very high metabolic levels by female pheromones, elimination of body heat is not an issue in B. mori. Indeed, if there a relationship with "surface area" in B. mori, it is far more likely to be tied to trachealsystem surface area. Within an instar, body mass of an insect can easily double, yet this increase in mass is not accompanied by an increase in the surface area of the tracheal system until the cuticle is shed during ecdysis. Simply on the basis of this morphometric limitation, it might be anticipated that this relative "underdevelopment" of the tracheal system during growth within an instar imposes limitations on gas exchange and that these limitations, in turn, would lead to lower-than-expected values of $b$ in the allometric equation for each instar. Yet, as evident from our data, values of $\dot{\mathrm{V}}_{2}$ actually increased sharply during growth within instars, reflected in values of $b$ in the range of $\sim 1$ for several instars, certainly higher than values that would be predicted from interspecific analysis. Recent studies on grasshoppers have shown that, at least for these insects, larval instars overcome static tracheal dimensions (and possible air sac compression) within instars by increasing tracheal ventilation rates during the development of that instar (Greenlee and Harrison 2004a, 2004b, 2005; Harrison et al. 2005). This physiological mechanism "dissociates" metabolic allometry from a potentially limiting morphological factor of fixed respiratory surface area.

Pupae may be a special case in allometry in several regards. Setting aside the intense apoptosis followed by hyperplastic and hypertrophic growth in the recreation of new body form, there is overall a well-documented U-shaped curve describing pupal metabolism in insects (see Odell 1998 for an entry into the literature). Given that there is also a steady decrease in pupal mass in insects during the pupation period, it is not surprising that the there is no clear relationship between metabolic rate and body mass.

\section{Conclusion}

Intraspecific allometric relationships for $\dot{\mathrm{V}}_{2}$ in Bombyx mori follow the general trend for interspecific allometric relationships of adult metazoans, namely, an increase in whole-animal $\dot{\mathrm{V}}_{2}$ with an increase in body mass. However, the scaling coefficient of 0.82 for Bombyx across development is in aggregate higher than that predicted by Kleiber's Law (0.75) or the Surface Law (0.67), both based on interspecific studies. Yet any value for an overall slope relating whole-animal (or mass-specific) $\dot{\mathrm{V}}_{2}$ to body mass in Bombyx will be somewhat an artifact of calculation, because within most instars the allometric relationship between whole-animal $\dot{\mathrm{V}}_{2}$ and body mass exhibits a value $(\sim 1)$ much higher than the overall value across development (0.82; Table 2). These observations support and extend the intraspecific analyses of Heusner (1982) and Glazier (2005), 
who also reported significant variation in metabolic scaling relationships within developmental stages in a wide variety of animals.

We conclude that neither Kleiber's Law nor the Surface Law accurately depict the complex metabolism-body mass relationships of growing insects passing through complex developmental stages, each characterized by a potentially different set of morphologies and enabling or compensating physiologies. Nonetheless, in comparisons of body mass and surface area as potential independent variables (Table 2), $\dot{\mathrm{V}}_{2}$ is best described as a function of body mass rather than of body surface area in developing B. mori.

Data from this study indicate that the decline in mass-specific oxygen consumption with progressive development between instars results primarily from a decline in the total number of mitochondrion-bearing cells (as predicted from the decline in cytochrome c oxidase, which is strongly correlated with mitochondrial density) and thus an overall decline in metabolic intensity, rather than from disproportional increases in nonmetabolic lipid stores or tissue water content. Thus, our study refutes the notion that mass-specific metabolic rate is driven by changes in proportion of tissues with intrinsically high or low metabolic rates. Indeed, higher-metabolic rate organs (e.g., gut, silk glands) grow proportionately faster than general body mass. Notably, however, the smaller instars (L-I-L-III) had the highest amount of mitochondrial cytochrome c oxidase activity per gram of body mass. This provides evidence that there are more metabolically active mitochondria per gram in these early larval stages and that their increased aerobic activity likely contributes to the higher mass-specific $\dot{\mathrm{V}}_{2}$ of the younger larvae.

After many decades of investigation, metabolic allometry during development remains simultaneously enigmatic and fascinating, especially in developing animals that show profound qualitative, as well as quantitative, changes as they proceed through developmental stages. It may prove that the impasse of principles discussed above (required constancy of physiological state for measurement vs. dynamic nature of physiological state innate to development) will demand new theoretical constructs for developmental allometry. Our study suggests that insects provide a tractable model with which to continue these studies.

\section{Acknowledgment}

This study was supported by National Science Foundation operating grant 0614815 to W.W.B.

\section{Literature Cited}

Agutter P.S. and D.N. Wheatley. 2004. Metabolic scaling: consensus or controversy? Theor Biol Med Model 16:1-13.

Baldwin K.M. and R.S. Hakim. 1991. Growth and differentiation of the larval midgut epithelium during molting in the moth, Manduca sexta. Tissue Cell 23:411-422.

Beckage N.E., D.B. Gelman, M.A. Chappell, and M. Alleyne.
1997. Effects of parasitism by the braconid wasp Cotesia congregata on metabolic rate in host larvae of the tobacco hornworm, Manduca sexta. J Insect Physiol 43:143-154.

Bennett V.A., O. Kukal, and R.E. Lee Jr. 1999. Metabolic opportunists: feeding and temperature influence the rate and pattern of respiration in the high arctic woollybear caterpillar Gynaephora groenlandica (Lymantriidae). J Exp Biol 202:4753.

Blossman-Myer B. and W.W. Burggren. 2010. The silk cocoon of the silkworm, Bombyx mori: macro structure and its influence on transmural diffusion of oxygen and water vapor. Comp Biochem Physiol A 155:259-263.

Bradley T.J. 1984. Mitochondrial placement and function in insect ion-transporting cells. Am Zool 24:157-167.

Burggren W.W. 2005. Developing animals flout prominent assumptions of ecological physiology. Comp Biochem Physiol A 141:430-439.

Cağlayan S.H. 1990. Changes in the chemical composition of fat body during the last larval instar of Manduca sexta. Acta Biol Hung 41:363-372.

Canavoso L.E., H.K. Yun, Z.E. Jouni, and M.A. Wells. 2004. Lipid transfer particle mediates the delivery of diacylglycerol from lipophorin to fat body in larval Manduca sexta. J Lipid Res 45:456-465.

Chamberlin M.E. 2007. Changes in mitochondrial electron transport chain activity during insect metamorphosis. Am J Physiol 292:R1016-R1022.

Chamberlin M.E., C.M. Gibellato, R.J. Noecker, and E.J. Dankoski. 1997. Changes in midgut active ion transport and metabolism during larval-larval molting in the tobacco hornworm (Manduca sexta). J Exp Biol 200:643-648.

Chown S.L., A.G. Gibbs, S.K. Hetz, C.J. Klok, J.R.B. Lighton, and E. Marais. 2006. Discontinuous gas exchange in insects: a clarification of hypotheses and approaches. Physiol Biochem Zool 79:333-343.

Cloudsley-Thompson J.L. 1975. Adaptations of Arthropoda to arid environments. Annu Rev Entomol 20:261-283.

Connor W.E., Y. Wang, M. Green, and D.S. Lin. 2006. Effects of diet and metamorphosis upon the sterol composition of the butterfly Morpho peleides. J Lipid Res 47:1444-1448.

Czarnołęski M., J. Kozłowski, G. Dumiot, J.-C. Bonnet, J. Mallard, and M. Dupont-Nivet. 2008. Scaling of metabolism in Helix aspersa snails: changes through ontogeny and response to selection for increased size. J Exp Biol 211:391-399.

Davies R. and C. Moyes. 2007. Allometric scaling in centrarchid fish: origins of intra- and inter-specific variation in oxidative and glycolytic enzyme levels in muscle. J Exp Biol 210:37983804.

D’Costa M.A. and L.M. Birt. 1966. Changes in the lipid content during the metamorphosis of the blowfly, Lucilia. J Insect Physiol 12:1377-1394.

Domroese K.A. and L.I. Gilbert. 1964. The role of lipid in adult development and flight muscle metabolism in Hyalophora cecropia. J Exp Biol 41:573-590.

Economo E.P., A.J. Kerkhoff, and B. Enquist. 2005. Allometric 
growth, life-history invariants and population energetics. Ecol Lett 8:353-360.

Edwards J. 1953. Insect Physiology. Wiley, New York.

Fast P. 1964. Insect lipids: a review. Mem Entomol Soc Can 37:3-50.

Feldman H.A. and T.A. McMahon. 1983. The 3/4 mass exponent for energy metabolism is not a statistical artifact. Respir Physiol 52:149-163.

Fernando-Warnakulasuriya G.J.P., K. Tsuchida, and M.A. Wells. 1988. Effect of dietary lipid content on lipid transport and storage during larval development of Manduca sexta. Insect Biochem 18:211-214.

Fugo H., S. Hitoshi, N. Hiromichi, and S. Akinori. 1984. Eclosion hormone activity in developing embryos of the silkworm, Bombyx mori. J Insect Physiol 31:293-298.

Ganga G. 2003. Comprehensive Sericulture. Vol. 2. Silkworm Rearing and Silk Reeling. Science, Enfield, NH.

Gibellato C.M. and M.E. Chamberlin. 1994. Midgut metabolism in different instars of the tobacco hornworm (Manduca sexta). J Exp Zool 270:405-409.

Glazier D. 2005. Beyond the "3/4-power law": variation in the intra-and interspecific scaling of metabolic rate in animals. Biol Rev Camb Philos Soc 80:661-662.

Grant J.B. 2006. Diversification of gut morphology in caterpillars is associated with defensive behavior. J Exp Biol 209: 3018-3024.

Gray E.M. and T. J. Bradley. 2006. Evidence from mosquitoes suggest that cyclic gas exchange and discontinuous gas exchange are two manifestations of a single respiratory pattern. J Exp Biol 209:1603-1611.

Greenlee K.J. and J.F. Harrison. 2004a. Development of respiratory function in the American locust Schistocerca americana. I. Across-instar effects. J Exp Biol. 207:497-508.

- 2004b. Development of respiratory function in the American locust Schistocerca americana. II. Within-instar effects. J Exp Biol 207:509-517.

- 2005. Respiratory changes throughout ontogeny in the tobacco hornworm caterpillar, Manduca sexta. J Exp Biol 208:1385-92.

Harrison J.F., J.J. Lafreniere, and K.J. Greenlee. 2005. Ontogeny of tracheal dimensions and gas exchange capacities in the grasshopper, Schistocerca americana. Comp Biochem Physiol A 141:372-380.

Hetz S.K. 2007. The role of the spiracles in gas exchange during development of Samia cynthia (Lepidoptera, Saturniidae). Comp Biochem Physiol A 148:743-754.

Hetz S.K. and T.J. Bradley. 2005. Insects breathe discontinuously to avoid oxygen toxicity. Nature 433:516-519.

Heusner A.A. 1982. Energy metabolism and body size. I. Is the 0.75 mass exponent of Kleiber's equation a statistical artifact? Respir Physiol 48:1-12.

Heyland A. and L.L. Moroz. 2006. Signaling mechanisms underlying metamorphic transitions in animals. Integr Comp Biol 46:743-759.

Hulbert A.J. and P.L. Else. 2005. Membranes and the setting of the energy demand. J Exp Biol 208:1593-1599.
Hunt von Herbing I. 2006. The physiological basis for metabolic scaling in animals: a developing perspective. Pp. 83-95 in S. Warburton, W.W. Burggren, B. Pelster, C. Reiber, and J. Spicer, eds. Comparative Developmental Physiology. Oxford University Press, New York.

Jouni Z.E. and M.A. Wells. 1996. Purification and partial characterization of a lutein-binding protein from the midgut of the silkworm Bombyx mori. J Biol Chem 271:14722-14726.

Kemp W.P., J. Bosch, and B. Dennis. 2004. Oxygen consumption during the life cycles of the prepupa-wintering bee Megachile rotundata and the adult-wintering bee Osmia lignaria (Hymenoptera: Megachilidae). Ann Entomol Soc Am 97:161-170.

Kleiber M. 1932. Body size and metabolism. Hilgardia 6:315349.

- 1975. The Fire of Life: An Introduction to Animal Energetics. Rev. ed. Krieger, Huntington, NY.

Kozłowski J. and M. Konarzewski. 2004. Is West, Brown and Enquist's model of allometric scaling mathematically correct and biologically relevant? Funct Ecol 18:283-289.

Levy R.I. and H.A. Schneiderman. 1966. Discontinuous respiration in insects. IV. Changes in intratracheal pressure during the respiratory cycle of silkworm pupae. J Insect Physiol 12:465-492.

Lighton J.R.B. 1996. Discontinuous gas exchange in insects. Annu Rev Entomol 41:309-24.

Mandel L.J., T.G. Riddle, and J.M. Storey. 1980. Role of ATP in respiratory control and active transport in tobacco hornworm midgut. Am J Physiol 238:C10-C14.

Matsuura S., T. Morimoto, S. Nagata, and Y. Tashiro. 1968. Studies on the posterior silk gland of the silkworm, Bombyx mori. II. Cytolytic processes in posterior silk gland cells during metamorphosis from larva to pupa. J Cell Biol 38:589603.

Moran D., B. Gara, and R.M.G. Wells. 2007. Energetics and metabolism of yellowtail kingfish (Seriola lalandi Valenciennes 1833) during embryogenesis. Aquaculture 265:359369.

Moran D. and R.M.G. Wells. 2007. Ontogenetic scaling of fish metabolism in the mouse-to-elephant mass magnitude range. Comp Biochem Physiol A 148:611-620.

Morimoto T., S. Matsuura, S. Nagata, and Y. Tashiro. 1968. Studies on the posterior silk gland of the silkworm, Bombyx mori. III. Ultrastructural changes of posterior silk gland cells in the fourth larval instar. J Cell Biol 38:604-614.

Moses M.E., C. Hou, W.H. Woodruff, G.B. West, J.C. Nekola, W. Zuo, and J.H. Brown. 2008. Revisiting a model of ontogenetic growth: estimating model parameters from theory and data. Am Nat 171:632-645.

Nespolo R.F., M.A. Lardies, and F. Bozinovic. 2003. Intrapopulational variation in the standard metabolic rate of insects: repeatability, thermal dependence and sensitivity $\left(Q_{10}\right)$ of oxygen consumption in a cricket. J Exp Biol 206:4309-4315.

Odell J.P. 1998. Energetics of metamorphosis in two holometabolous insect species: Manduca sexta (Lepidoptera: Sphin- 
gidae) and Tenebrio molitor (Coleoptera: Tenebrionidae). J Exp Zool 280:344-353.

Ojeda-Avila T., H.A. Woods, and R.A. Raguso. 2003. Effects of dietary variation on growth, composition, and maturation of Manduca sexta (Sphingidae: Lepidoptera). J Insect Physiol 49:293-306.

Parenti P., B. Giordana, V.F. Sacchi, G.M. Hanozet, and A. Guerritore. 1985. Metabolic activity related to the potassium pump in the midgut of Bombyx mori larvae. J Exp Biol 116: 69-78.

Patel R.T., J.L. Soulages, B. Hariharasundaram, and E.L. Arrese. 2005. Activation of the lipid droplet controls the rate of lipolysis of triglycerides in the insect fat body. J Biol Chem 280:22624-22631.

Powers D.R. and T.M. Conley. 1994. Field metabolic rate and food consumption in two sympatric hummingbird species in southeastern Arizona. Condor 96:141-150.

Prasad S.V., R.O. Ryan, J.H. Law, and M.A. Wells. 1986. Changes in lipoprotein composition during larval-pupal metamorphosis of an insect, Manduca sexta. J Biol Chem 261:558562.

Rockstein M. 1973. The Physiology of Insecta. Academic Press, New York.

Sasaki S. and Y. Tashiro. 1976. Studies on the posterior silk gland of the silkworm, Bombyx mori. V. Electron microscope localization of fibroin in the posterior silk gland at the later stage of the fifth instar. J Cell Biol 70:648-659.

Satake S., Y. Kawabe, and A. Mizoguchi. 2000. Carbohydrate metabolism during starvation in the silkworm Bombyx mori. Arch Insect Biochem Physiol 44:90-98.

Schmidt-Nielsen K. 1984. Scaling: Why Is Animal Size So Important? Cambridge University Press, Cambridge.

Schroeder L. and D.G. Dunlap. 1970. Respiration of cecropia moth (Hyalophora cecropia L.) larvae. Comp Biochem Physiol 35:953-957.

Seibel B.A. 2007. On the depth and scale of metabolic rate variation: scaling of oxygen consumption rates and enzymatic activity in the class Cephalopoda (Mollusca). J Exp Biol 210:1-11.

Smith R.L. 1984. Allometric scaling in comparative biology: problems of concept and method. Am J Physiol 246:R152R160.

Stusek P., F. Pohleven, and D. Capl. 2000. Detection of wood boring insects by measurement of oxygen consumption. Int Biodeterior Biodegrad 46:293-298.

Syed Z., Y. Ishida, K. Taylor, D.A. Kimbrell, and W.S. Leal. 2006. Pheromone reception in fruit flies expressing a moth's odorant receptor. Proc Natl Acad Sci USA 103:16538-16543.

Tashiro Y., T. Morimoto, S. Matsuura, and S. Nagata. 1968. Studies on the posterior silk gland of the silkworm, Bombyx mori. I. Growth of posterior silk gland cells and biosynthesis of fibroin during the fifth larval instar. J Cell Biol 38:574588.

Tenney S.M. 1985. Oxygen supply and limiting oxygen pressures in an insect larva. Respir Physiol 60:121-134.

Tojo S., T. Betchaku, V.J. Ziccardi, and G.R. Wyatt. 1978. Fat body protein granules and storage proteins in the silkmoth, Hyalophora cecropia. J Cell Biol 78:823-838.

Toledo L.E., S.P. Brito, W.K. Milsom, A.S. Abe, and D.V. Andrade. 2008. Effects of season, temperature, and body mass on the standard metabolic rate of tegu lizards (Tupinambis merianae). Physiol Biochem Zool 81:158-164.

Uchimura K., H. Ai, K. Kuwasawa, T. Matsushita, and M. Kurakawa. 2005. Excitatory neural control of posterograde heartbeat by the frontal ganglion in the last instar larva of a lepidopteran, Bombyx mori. J Comp Physiol A 192:175185.

Wang Z.-M., R.N. Pierson Jr., and S.B. Heymsfield. 1992. The five-level model: a new approach to organizing bodycomposition research. Am J Clin Nutr 56:19-28.

West G.B. and J.H. Brown. 2005. The origin of allometric scaling laws in biology from genomes to ecosystems: towards a quantitative unifying theory of biological structure and organization. J Exp Biol 208:1575-1592.

West G.B., W.H. Woodruff, and J.H. Brown. 2002. Allometric scaling of metabolic rate from molecules and mitochondria to cells and mammals. Proc Natl Acad Sci USA 99:24732478.

White C.R. and R.S. Seymour. 2003. Mammalian basal metabolic rate is proportional to body mass ${ }^{2 / 3}$. Proc Natl Acad Sci 100:4046-4049.

Wieser W. 1984. A distinction must be made between the ontogeny and the phylogeny of metabolism in order to understand the mass exponent of energy metabolism. Respir Physiol 55:1-9.

Withers P.C. 1992. Comparative Animal Physiology. Saunders, Fort Worth, TX. 
Copyright of Physiological \& Biochemical Zoology is the property of University of Chicago Press and its content may not be copied or emailed to multiple sites or posted to a listserv without the copyright holder's express written permission. However, users may print, download, or email articles for individual use. 